\title{
Comunidade de aranhas orbitelas (Araneae, Arachnida) na região da Reserva Florestal do Morro Grande, Cotia, São Paulo, Brasil
}

\author{
André do Amaral Nogueira', Ricardo Pinto-da-Rocha ${ }^{1} \&$ Antonio D. Brescovit ${ }^{2}$
}

Biota Neotropica v6 (n2)-http://www.biotaneotropica.org.br/v6n2/pt/abstract?article+bn00906022006

\author{
Recebido em 11/3/2004 \\ Versão reformulada recebida em 21/3/2005 \\ Publicado em 01/05/2006
}

${ }^{1}$ Departamento de Zoologia, Instituto de Biociências, Universidade de São Paulo, Caixa Postal 11461, 05422-970 São
Paulo, SP (autor para correspondência: andrenog@ib.usp.br)
${ }^{2}$ Laboratório de Artrópodes Peçonhentos, Instituto Butantan, Av. Vital Brasil, 1500, 05530-900 São Paulo, SP

\begin{abstract}
Nogueira, A.A.; Pinto-da-Rocha, R. and Brescovit, A.D. Orb-weavers spiders (Arachnida-Araneae) community in the Reserva Florestal do Morro Grande region, Cotia, São Paulo State, Brazil. Biota Neotrop. May/Aug 2006 vol. 6 no. 2 , http://www.biotaneotropica.org.br/v6n2/pt/abstract?article+bn00906022006. ISSN 1676-0603
\end{abstract}

An inventory of the orb-weaver spiders guild was carried out at the Reserva Florestal do Morro Grande and nearby regions (Cotia and Ibiúna-SP). Sixteen areas were sampled, eight belonging to the Reserve, and eight to forest fragments. Four areas of the Reserve presented a mature vegetation, while the remaining four, as well as the forest fragment areas, presented secondary vegetation. Sampling was carried out in December 2002 and March 2003, and the method employed was the nocturnal manual searching. Twenty four samples were obtained from each area, totalling 384 samples. A total of 12,683 spiders were collected, 3,148 adults (24.8\%), and 9,535 immatures (75,2\%). Adult spiders were sorted to 121 species, belonging to seven families. This is the largest richness ever recorded for an Atlantic Forest area. Both sampling periods had 67 species in common and 27 exclusive species. The most species rich family was Araneidae (76 spp), followed by Tetragnathidae (26 spp), Theridiosomatidae (nine spp), Uloboridae (six spp), Anapidae (two spp), Mysmenidae (one sp) and, Symphytognathidae (one sp). The distribution of the species among the families agrees with their richness in Brazil and worldwide, except Theridiosomatidae witch seems to be overepresented. Their relative abundance showed a similar pattern. The dominant species was Micrathena nigrichelis, with 320 specimens, followed by Micrathena guanabara (306 individuals), Mangora sp.2 (258 individuals) and, Wagneriana janeiro (171 individuals). The community presented a low dominance $\left(H^{\prime}=3.11\right)$ and a high evenness $(E=0.835)$, as expected in a tropical environment. Seven non-parametric richness estimators were used, and their estimates ranged from 130.9 (Bootstrap) to 155.9 (Jackknife 2) species. Nevertheless, none of them reached the asymptote, since the number of rare species (singletons, doubletons, uniques and duplicates) remained stable. The distribution of the species among the eight areas of the Reserva do Morro Grande was verified by a DCA, and the results showed a clear distinction between mature and secondary forests. This analysis also showed species related to each kind of environment, and the results were compared to those of other inventories. The large number of species and individuals of orb-weaver spiders collected stresses the importance of the studied forests and especially the Reserva do Morro Grande as a conservation unit.

Key words: Orb-weaver spiders, biodiversity, Atlantic Forest, Brazil, Reserva Florestal do Morro Grande.. 


\section{Resumo}

Nogueira, A. A.; Pinto-da-Rocha, R. and Brescovit, A. D. Comunidade de aranhas orbitelas (Arachnida-Araneae) na região da Reserva Florestal do Morro Grande, Cotia, São Paulo, Brasil. Biota Neotrop. May/Aug 2006 vol. 6 no. 2, http:// www.biotaneotropica.org.br/v6n2/pt/abstract?article+bn00906022006. ISSN 1676-0603

Foi realizado um levantamento da fauna de aranhas orbitelas da Reserva Florestal do Morro Grande e região (Cotia e Ibiúna-SP). Foram amostradas 16 áreas, oito na reserva e oito em fragmentos florestais. Quatro das áreas da reserva possuíam uma vegetação madura, enquanto as outras apresentavam vegetação secundária, assim como os fragmentos. As amostragens foram realizadas em dezembro de 2002 e março de 2003, e o método empregado foi a coleta manual noturna. Obteve-se um total de 384 amostras, correspondendo a 24 por área. Foram obtidas 12.683 aranhas orbitelas, 3.148 das quais adultas (24,8\%) e 9.535 jovens (75,2\%). As adultas foram distribuídas em 121 espécies, pertencentes a sete famílias. Tratase da maior riqueza já observada para a guilda em áreas de Mata Atlântica. Cada período de coleta apresentou 27 espécies exclusivas, e 67 estiveram presentes em ambos. A família mais rica foi Araneidae (76 spp), seguida por Tetragnathidae (26 spp), Theridiosomatidae (nove spp), Uloboridae (seis spp), Anapidae (duas spp), Mysmenidae (uma sp) e Symphytognathidae (uma sp). A distribuição das espécies pelas famílias parece refletir a riqueza desses grupos no Brasil e no mundo, com exceção de Theridiosomatidae, que teve um número de espécies maior do que o esperado. A abundância relativa dessas famílias apresentou padrão semelhante ao da riqueza. A espécie dominante foi Micrathena nigrichelis, com 320 indivíduos, seguida por Micrathena guanabara (306 indivíduos), Mangora sp.2 (258 indivíduos) e Wagneriana janeiro (171 indivíduos). A comunidade apresentou uma baixa dominância $\left(H^{\prime}=3,11\right)$ e alta equitabilidade $(E=0,835)$, estando de acordo com o esperado para ambientes tropicais. Foram empregados sete estimadores de riqueza não paramétricos, e as estimativas variaram entre 130,9 (Bootstrap) e 155,9 (Jackknife 2) espécies. No entanto, apesar do grande esforço amostral (intensidade de coleta de 26:1), nenhum dos estimadores atingiu a asíntota, uma vez que o número de espécies raras (singletons, doubletons, uniques e duplicates) permaneceu estável. A distribuição das espécies entre as oito áreas da Reserva do Morro Grande foi verificada através de uma (DCA), e os resultados mostraram que houve uma separação entre as áreas de vegetação madura e as de vegetação secundária. A análise também apontou espécies associadas a cada um desses ambientes, e os resultados foram comparados aos encontrados em outros inventários. O grande número de espécies e indivíduos de aranhas orbitelas encontrados neste trabalho ressalta a importância das florestas da área de estudo e principalmente da Reserva do Morro Grande como unidade de conservação.

Palavras-chave: Aranhas orbitelas, biodiversidade, Floresta Atlântica, Brasil, Reserva Florestal do Morro Grande. 


\section{Introdução}

As aranhas possuem mais de 39.000 espécies descritas, divididas em 110 famílias (Platnick 2006), são encontradas em todos os ambientes, exceto os pólos, sendo abundantes em locais de vegetação exuberante (Foelix 1996). Todas são predadoras e alimentam-se de uma grande variedade de presas (Nyffeler et al. 1994), sobretudo insetos (Nentwig 1989). Por estarem no topo da cadeia alimentar dos invertebrados (Coddington et al. 1991) e pela sua alta diversidade e abundância, as aranhas possuem relevante importância ecológica (Coddington et al. 1991, Churchill 1997), e podem ser utilizadas em monitoramentos ambientais (New 1999).

O uso de aranhas como indicadores biológicos vem sendo proposto como parte de um esforço desenvolvido para incluir invertebrados em questões referentes a políticas de conservação (New 1999), tradicionalmente voltadas para vertebrados. Acredita-se que a riqueza e abundância das aranhas possam refletir a de artrópodes pertencentes a níveis tróficos inferiores. As aranhas também são sensíveis a mudanças bióticas e abióticas do ambiente (Foelix 1996), e podem ser coletadas em grande abundância de maneira rápida e barata, mesmo em pequenas escalas espaciais, o que facilita o tratamento estatístico da amostragem.

O estudo de uma ou algumas famílias ou guildas ao invés de toda a araneofauna pode aumentar o valor informativo dos dados (Churchill 1997, New 1999), já que uma determinada guilda costuma ter uma relação mais específica com o ambiente, ou com um determinado grupo que lhe sirva de presa. Aranhas errantes de solo poderiam estar relacionadas à qualidade da serapilheira e à abundância de presas nesse estrato, enquanto a diversidade das construtoras de teia seria influenciada pelo tipo de vegetação arbórea e arbustiva. Por fim, o uso de uma ou poucas guildas implica menor custo e trabalho para amostrar e identificar o material, o que pode ser uma vantagem considerável ao se lidar com grupos muito diversos como as aranhas, sobretudo no caso de monitoramentos mais longos (Sorensen et al. 2002).

O conceito de guildas foi amplamente adotado por aracnólogos (Uetz et al. 1999). A maioria das aranhas é predadora generalista, exibindo uma enorme diversidade de estratégias para capturar suas presas. Isto inclui desde a procura ativa e a emboscada ("sit and wait") até o uso de diversos tipos de armadilhas de seda, as teias.

Uma das guildas mais diversas e abundantes é a das aranhas que tecem teias orbiculares, provavelmente o tipo de teia mais conspícuo e familiar (Figuras 1-2). Trata-se, em geral, de uma estrutura bidimensional, que se prende à vegetação através dos fios radiais, que convergem para o centro da teia. A parte da teia que serve como armadilha para reter presas é a espiral de captura, composta por fios cobertos por um líquido viscoso, e que vai da margem até o centro da teia (Foelix 1996). A predominância de presas aladas nesse tipo de teia, aliada a outras evidências, inclusive registros fósseis, sugere que elas evoluíram paralelamente ao desenvolvimento do vôo dos insetos (Coddington 1990).

As sete famílias pertencentes a essa guilda podem ser divididas em dois grupos, de acordo com Höfer \& Brescovit (2001): as orbitelas diurnas de chão (Anapidae, Mysmenidae e Symphytognathidae), e as orbitelas aéreas (Araneidae, Tetragnathidae, Theridiosomatidae e Uloboridae). O primeiro grupo reúne aranhas de tamanho diminuto ( $<5 \mathrm{~mm}$ ), que tecem pequenas teias orbiculares na serapilheira e em outros lugares próximos ao solo (DippenaarSchoeman \& Jocqué 1997). São famílias pouco diversas, das quais a melhor representada é Anapidae, com 143 espécies (Platnick 2004). O segundo grupo reúne espécies que são em média maiores (até 30-40 mm), sobretudo as das famílias Araneidae (Figuras 3-8) e Tetragnathidae (Dippenaar-Schoeman \& Jocqué 1997). Ocorrem principalmente no subosque, onde podem ocupar diversos microhabitats (Silva 1996). As famílias mais ricas em espécies dessa guilda são Araneidae (2.823 espécies) e Tetragnathidae (1.021 espécies). A exemplo do que ocorre com a araneofauna de modo geral, a maioria dos membros desse grupo tem hábitos noturnos, pelo menos em ambientes tropicais (Rypstra 1986, Coddington et al. 1996). Levantamentos de araneofauna realizados em ambientes florestais mostram que as aranhas orbitelas são importantes componentes da comunidade, representando de 15\% até mais de $50 \%$ da riqueza e abundância total, tanto em ambientes temperados (Coddington et al. 1996, Scharff et al. 2003) como tropicais (Silva \& Coddington 1996, Brescovit et al. 2004b).

Os primeiros trabalhos sobre diversidade de aranhas no Brasil são basicamente listas de ocorrência de espécies, realizados na Mata Atlântica, sobretudo em áreas da Serra do Mar e em ilhas (Mello-Leitão 1923, Luederwaldt 1929, Bücherl 1949). Outras localidades desse bioma amostradas mais recentemente foram a Ilha do Cardoso (SP), em um trabalho que se restringiu à araneofauna de solo (Fowler \& Venticinque 1995), e a Estação Ecológica Juréia-Itatins, abrangendo araneofauna de solo e subosque (Brescovit et al. 2004a). Existem ainda cerca de 15 inventários em andamento ou já concluídos que devem ser publicados em breve, como o de Santos (1999), realizado em Linhares (ES), e o de Pinto-da-Rocha no Parque Estadual da Serra da Cantareira (SP).

Com exceção da Mata Atlântica e da Amazônia, palco de alguns levantamentos aracnológicos realizados principalmente a partir dos anos 90 (Höfer et al. 1994, Borges \& Brescovit 1996, Martins \& Lise 1997, Lise 1998, Höfer \& Brescovit 2001), a quantidade de estudos dessa natureza em outros ecossistemas brasileiros é bastante escassa. 
Os objetivos deste trabalho foram inventariar e estimar a riqueza e analisar a estrutura da comunidade de aranhas orbitelas na Reserva do Morro Grande (Cotia-SP) e região, e comparar os resultados com os obtidos em outros levantamentos realizados na Mata Atlântica.

\section{Material e Métodos}

\section{1. Área de estudo}

Foram selecionadas oito áreas para amostragem na reserva, quatro delas compostas por vegetação secundária em estádio avançado e quatro áreas de vegetação mais madura. As áreas maduras amostradas foram Capelinha, Quilombo, Grilos e Torres, e as secundárias foram denominadas A, B, C e D. Além delas, foram também amostrados oito fragmentos florestais nos municípios de Cotia e Ibiúna (SP), vizinhos à Reserva (ver figura 13 em Metzger et al. 2006).

\section{Amostragem}

O método utilizado foi a coleta manual noturna, onde o coletor, com o auxílio de lanterna de cabeça, procura aracnídeos desde o solo até a altura que puder alcançar, investigando a vegetação, troncos caídos e outros microhabitats. Os aracnídeos foram capturados com o auxílio de pinças, frascos ou com as mãos, e fixados em álcool 70\%. Cada amostra representou 1 hora de procura por coletor ao longo de um transecto de $30 \mathrm{~m}$ de comprimento, do qual pode se afastar cerca de $5 \mathrm{~m}$ para cada lado, totalizando cerca de $300 \mathrm{~m}^{2}$.

Cada uma das 16 áreas foi amostrada por duas noites, uma na primeira expedição de coleta (dezembro de 2002), e outra na segunda (março de 2003). Cada coletor fez três amostras a cada vez, totalizando 12 amostras por noite, uma vez que as equipes de coleta eram compostas por quatro membros. Ao término dos trabalhos de campo tivemos 24 amostras por local, totalizando 384 amostras.

Os transectos foram estendidos durante o dia, para não danificar teias noturnas e espantar as aranhas, a pelo menos 100 metros da borda das matas para minimizar os efeitos de borda e com uma distância mínima de 20 metros entre cada, para evitar sobreposição nas amostragens. Em dezembro as coletas começavam entre 20:30 e 21:00 h (horário de verão), e em março, entre 19:30 e 20:00 h. A cada noite uma área era amostrada. As coletas só não foram realizadas em noites chuvosas, ou em dias com chuvas prolongadas, que paravam pouco antes do anoitecer.

O material testemunho está depositado nas coleções do Museu de Zoologia da USP e Instituto Butantan. Os jovens foram identificados até o nível de família, e os adultos foram morfoespeciados, isto é, agrupados em unidades equivalentes à espécie. Em seguida, foram identificados até o nível taxonômico mais preciso possível. Os machos e fêmeas foram pareados com base principalmente nas semelhanças de coloração e morfologia, embora também tenha sido levado em conta a procedência (localidade de coleta). As determinações foram realizadas pelo primeiro autor e conferidas pelo terceiro.

\section{Análises estatísticas}

A riqueza observada foi representada através de uma curva média de acumulação de espécies (ou curva do coletor), que relaciona o número de espécies obtidas ao aumento do esforço de coleta. Uma vez que a ordem de entrada das amostras pode mudar o formato da curva, foi calculada uma média para cada ponto de esforço amostral a partir dos dados de 100 curvas nas quais a ordem de entrada das amostras foi aleatorizada.

Foram utilizados sete estimadores não-paramétricos de riqueza: Jackknife 1 e 2, Chao 1 e 2, ACE, ICE e Bootstrap. Os seis primeiros baseiam-se na proporção de espécies raras em relação à riqueza total observada. As medidas de raridade empregadas pelos quatro primeiros estimadores são: espécies representadas por apenas um (singleton) ou dois indivíduos (doubleton) em toda amostragem, ou; espécies que ocorrem em apenas uma (unique) ou duas amostras (duplicate). Para os estimadores ACE e ICE considerou-se uma abundância de até 10 indivíduos (ACE), ou presença em até 10 amostras (ICE). O Bootstrap difere dos demais por utilizar dados de todas as espécies coletadas para estimar a riqueza total, através da soma da riqueza observada com o inverso da proporção de amostras em que ocorre cada espécie. Uma descrição mais detalhada dos métodos, incluíndo as fórmulas, pode ser encontrada em Santos (2003). As estimativas foram calculadas no programa EstimateS versão 5.0.1 (Colwell 1997).

A diversidade da comunidade foi verificada através do Índice de Shannon (H') e o Índice de Equitabilidade de Shannon (E), que é a razão entre a diversidade observada e a diversidade máxima, que ocorreria quando todas as espécies registradas apresentassem o mesmo número de indivíduos. Para as descrições dos índices e as fórmulas, vide Magurran (1988).

Também foi calculada a intensidade de coleta, que é a razão do número de indivíduos sobre o número de espécies (Coddington et al. 1996). Trata-se de um parâmetro utilizado para medir o esforço amostral, que pode ter grande influência sobre o desempenho dos estimadores.

Foi realizada uma Análise de Correspondência Destendenciada (DCA) para verificar a similaridade da fauna de aranhas orbiculares entre as oito áreas da reserva. A análise foi realizada com todas as 100 espécies presentes na Reserva, através do programa MVSP, versão 3.1 (Kovach 2000). 
As diferenças na riqueza e abundância entre as áreas da Reserva serão testadas posteriormente, em outro trabalho, que incluirá também comparações entre essas áreas e os fragmentos, analisados através de análises de variância e ordenações.

\section{Resultados}

Foram obtidas 12.683 aranhas orbitelas, das quais 3.148 adultas $(24,8 \%)$ e 9.535 jovens $(75,2 \%)$. As adultas foram distribuídas em 121 espécies, pertencentes a sete famílias (Tabela 1). Cada período de coleta apresentou 27 espécies exclusivas, e 67 estiveram presentes nos dois períodos. A lista completa com todas as espécies e a abundância de cada uma nas diferentes áreas pode ser vista na Tabela 2. O número de aranhas encontrado na Reserva do Morro Grande (100 espécies, 1.917 adultos e 4.909 jovens) foi maior do que o obtido nos fragmentos (91 espécies, 1.231 adultos e 4.626 jovens). A Reserva também apresentou um maior número de espécies exclusivas (30 contra 21 dos fragmentos).

As famílias Araneidae e Tetragnathidae foram responsáveis por 84,3\% do total de espécies, 92,1\% do total de adultos e 98,5\% de jovens. Theridiosomatidae e Uloboridae apresentaram bem menos espécies, nove $(7,4 \%)$ e seis $(4,9 \%)$, e uma abundância de adultos ainda menor (5,3\% e 1,9\% respectivamente), enquanto a abundância de jovens variou bastante entre elas $(0,04 \%$ do total para Theridiosomatidae e 1,4\% para Uloboridae). As três famílias restantes, orbitelas de solo, foram representadas por poucas espécies e indivíduos, e juntas somaram apenas 3,3\% do total de espécies, 0,6\% da abundância de adultos e 0,01\% do total de jovens.

Os gêneros mais ricos (todos Araneidae) foram Alpaida (16 espécies, Figura 5), Araneus (10 spp, Figura 4) e Micrathena (sete spp, Figura 6), sendo que a maioria (52\%) dos gêneros foi representado por apenas uma ou duas espécies. Quanto à abundância, Micrathena apresentou os maiores valores (741 indivíduos), seguido por Chrysometa, (Tetragnathidae, 351 indivíduos), Mangora (Araneidae, 343 indivíduos, Figuras 7 e 8) e Araneus (293 indivíduos).

A comunidade apresentou alta diversidade $\left(\mathrm{H}^{\prime}=3,11\right)$ e equitabilidade $(E=0,835)$. O perfil da comunidade pode ser visto na Figura 9, que mostra um padrão esperado para comunidades tropicais, com poucas espécies dominantes e muitas espécies raras. A espécie mais abundante, Micrathena nigrichelis (320 indivíduos), representou apenas 10\% do número total de indivíduos, e somente quatro espécies tiveram uma abundância relativa de ao menos 5\% do número total de adultos (Micrathena nigrichelis-10\%, M. guanabara10\%, Mangora sp.2-8\% e Wagneriana janeiro-5\%).

As estimativas de riqueza variaram entre 130,9 para o Bootstrap até 155,9 para o Jackknife 2 (Figura 10). Esses valores sugerem que foram obtidos de $77 \%$ a $92 \%$ da fauna acessível aos nossos métodos, e que se encontrava adulta na época do levantamento. Na Figura 11 são apresentados o número de singletons, doubletons, uniques e duplicates. A intensidade de coleta foi de 26:1. Nem a curva do coletor, nem nenhum dos estimadores atingiu a assíntota (Figura 10), um indício de que o inventário ainda está incompleto e as estimativas provavelmente estão abaixo da riqueza real, o que não é surpreendente para uma comunidade de artrópodes tropicais. Após um aumento inicial, o número de singletons e uniques diminui e permanece estável, enquanto o de doubletons e duplicates diminuiu (Figura 11).

A Análise de Correspondência Destendenciada (Figura 12) mostra a formação de dois grupos, com as áreas de floresta madura de um lado, e as que possuem uma vegetação secundária do outro. A separação entre as áreas ocorreu no primeiro eixo, que explicou 38,2\% da variância observada nos dados e foi muito mais importante do que o segundo, que teve um valor de 8,1\%.

As espécies associadas às áreas de mata madura e áreas secundárias são apresentadas na Tabela 3. As listas dessa tabela levaram em conta apenas a distribuição das 37 espécies mais abundantes, que tiveram ao menos 10 indivíduos coletados. Esse procedimento foi adotado por se considerar que as espécies mais raras são pouco informativas, uma vez que a ausência de uma determinada área poderia ser conseqüência da dificuldade de coletar esses animais. No entanto, o critério adotado para a inclusão de espécies nessas listas (mínimo de 10 indivíduos) foi arbitrário. O grau de associação das espécies aos dois tipos de mata foi bastante variável, e foi determinado com base na localização das espécies em relação às áreas no primeiro eixo da Figura 12.

As espécies localizadas nas extremidades do primeiro eixo foram as mais associadas a seus respectivos tipos de matas. Elas apresentaram uma distribuição exclusiva ou muito concentrada, como Chrysometa cambara (25 indivíduos nas matas maduras), Mangora sp.5 (48 indivíduos nas matas maduras, quatro nas secundárias), Azilia sp.1 (10 indivíduos nas matas secundárias) e Wagneriana janeiro (59 indivíduos nas matas secundarias e dois nas maduras). Essas espécies também estiveram bem distribuídas entre as áreas de seus respectivos tipos de mata, ocorrendo de maneira bastante homogênea na maioria delas. As espécies mais afastadas das extremidades do gradiente, por sua vez, apresentam uma distribuição mais homogênea entre os dois tipos de mata, como Alpaida pedro (11 indivíduos nas matas maduras e nove nas secundárias) e Ogulnius sp.1 (25 indivíduos nas matas secundárias, 20 nas maduras), por exemplo. Dessa maneira, essas espécies não mostraram uma associação muito forte com nenhum tipo de vegetação, ao contrário do que ocorre com as espécies mais próximas do topo das listas da Tabela 3. 


\section{Discussão}

\section{Riqueza e abundância}

O presente levantamento obteve a maior riqueza já registrada para o grupo em áreas de Mata Atlântica, como pode ser visto na Tabela 4. O esforço amostral empregado em Morro Grande e região, medido tanto pelo número de indivíduos, amostras, ou pela intensidade de coleta, foi maior que nos outros levantamentos. Ainda que o inventário realizado na Cantareira tenha tido um maior número de amostras em geral, no presente levantamento houve uma maior quantidade de amostras manuais noturnas. Trata-se de um dos métodos mais eficientes em levantamentos de araneofauna, obtendo um grande número de indivíduos e espécies (Coddington et al. 1996, Silva \& Coddington 1996, Scharff et al. 2003), especialmente para as orbitelas. Parte dessa eficiência deve ser creditada às teias orbiculares que geralmente são montadas em locais mais abertos, entre plantas (Höfer \& Brescovit 2001, Blanco-Vargas et al. 2003), o que as deixa mais expostas. Um exemplo dessa eficiência pode ser encontrado nos dados do inventário do Parque Estadual da Cantareira, onde esse método obteve 66 espécies de aranhas orbitelas, o que equivale a $91,6 \%$ do total registrado para o grupo no local.

Outro fato importante foi o número de áreas amostradas, maior do que o observado nos outros levantamentos, e por elas encontrarem-se em diferentes estádios de desenvolvimento. A importância desse aspecto é evidenciada pela relação da estrutura e composição da vegetação com a araneofauna (Borges \& Brescovit 1996, Toti et al. 2000). A realização das coletas em dois meses diferentes também contribuiu para aumentar a riqueza observada, como pode ser visto pelo número de espécies exclusivas de cada mês (27). Isso, no entanto, não é surpresa, uma vez que existem vários registros na literatura de mudanças na composição da araneofauna ao longo do tempo (Abraham 1983, Churchill \& Arthur 1999, Norris 1999, Santos 1999, Toti et al. 2000, Majadas \& Urones 2002, Blanco-Vargas et al. 2003), embora geralmente as comparações sejam feitas entre diferentes estações. Ainda assim, alguns trabalhos (Lubin 1978, Dippenaar-Schoeman et al. 1989) mostram mudanças significativas na composição em intervalos de tempo menores, como no presente trabalho. Isso deve ocorrer porque o tempo de maturação e longevidade varia de acordo com a espécie.

A concentração das amostragens no período de maior oferta de recursos, a estação chuvosa, também deve ter contribuído para aumentar a riqueza (Levings \& Windsor 1984, Nentwig 1989), esta estação concentra o pico de abundância (Lubin 1978) e riqueza da araneofauna, e é a época de reprodução da maioria das espécies (Santos 1999). Por fim, a concentração do esforço amostral em períodos mais próximos permite que se amostre de maneira mais pro- funda a fauna estudada (Scharff et al. 2003), o que pode ser essencial para obter as espécies menos freqüentes. Portanto, inventários que distribuem seu esforço de coleta em vários períodos ou em diferentes estações podem estar diluindo seu esforço amostral e realizando uma coleta mais superficial, o que pode ser o caso dos outros levantamentos da Mata Atlântica.

Devido às diferenças metodológicas expostas acima, fica difícil concluir qual das áreas da Mata Atlântica é efetivamente mais rica, mas, em conseqüência do grande esforço amostral concentrado em um período extremamente produtivo, acreditamos que a comunidade amostrada em Morro Grande e região esteja representada de maneira mais completa do que ocorre com os outros levantamentos existentes para esse ecossistema.

Vale a pena ainda mencionar que inventários realizados em algumas áreas da Amazônia obtiveram um número maior de espécies do grupo, porém, o emprego de técnicas especialmente produtivas de coleta, como a fumigação (Silva 1996, Höfer \& Brescovit 2001), acrescentadas de um esforço amostral de vários anos (no caso de Höfer \& Brescovit 2001) torna os resultados ainda mais difíceis de serem comparados, embora existam algumas evidências, fornecidas também por outros levantamentos (Silva \& Coddington 1996, Córdova \& Duarez 2001) de que as áreas amazônicas sejam efetivamente muito ricas.

\section{Estimativas de riqueza}

As estimativas provavelmente estão subestimadas, o que implica uma maior porcentagem de espécies por ser descoberta na área. A comparação com outros inventários fica prejudicada por conta disto (Santos 2003), e principalmente pelo fato de que esses outros trabalhos referem-se a toda araneofauna.

A assíntota não foi atingida mesmo tendo sido obtidos mais de dois terços da riqueza total estimada. Sorensen et al. (2002), estudando uma floresta tropical africana, sugeriram que a estabilidade dos estimadores só pode ser atingida quando a intensidade de coleta apresentar valores de 30:1 a 50:1, valor não atingido no presente estudo. De qualquer maneira, nossos resultados assemelham-se ao encontrado em outros inventários, uma vez que é raro obter estimativas assintóticas para comunidades de aranhas. Quando isso ocorreu, as comunidades não apresentaram grande diversidade, como as das matas secundárias dos Andes Colombianos (Blanco-Vargas et al. 2003), ou de uma floresta temperada na Dinamarca (Scharff et al. 2003).

De maneira geral, o comportamento dos estimadores foi semelhante ao observado em outros trabalhos. O Bootstrap foi o estimador mais conservador em Toti et al. (2000) e Sorensen et al. (2002), enquanto o Jackknife 2 foi responsável pela maior estimativa em quatro casos (Santos 1999, Toti et al. 2000-área de brejo, Sorensen et al. 2002, 
Pinto-da-Rocha, dados não publicados) e pela segunda maior em três outros (Coddington et al. 1996, Toti et al. 2000-área de campo, Scharff et al. 2003).

A ausência de estimativas assíntóticas no presente trabalho está diretamente relacionada ao fato de que o número de espécies raras permaneceu estável.

\section{Estrutura e composição}

A comunidade de aranhas orbitelas exibiu o padrão típico esperado para comunidades de organismos tropicais, apresentando baixa dominância e, conseqüentemente, alta equitabilidade. A espécie dominante representou 10\% do total de adultos, enquanto em ambientes temperados a espécie dominante costuma contar com mais de 15\% do total de indivíduos (Toti et al. 2000, Majadas \& Urones 2002, Scharff et al. 2003), podendo chegar até mais de 50\%, em casos extremos (Toti et al. 2002). As diferenças entre os dois tipos de comunidade podem ser visualizadas ao compararmos a curva de abundância da figura 9 com a exibida em Scharff et al. (2003), referente à araneofauna de uma floresta de coníferas da Dinamarca.

A distribuição das espécies entre as famílias de orbitelas observada no presente trabalho parece refletir a riqueza dessas famílias no mundo (Platnick 2004) e no Brasil, como pode ser visto na Tabela 5 . O pequeno número de espécies das famílias de orbitelas de solo poderia ser atribuído a dificuldade de coletar esses animais através de um método baseado na procura visual, uma vez que são animais muito pequenos e que montam suas teias em locais mais abrigados. Da mesma maneira, a baixa riqueza no Brasil e no mundo dessas três famílias também poderia ser conseqüência dessas características. No entanto, mesmo inventários que utilizaram outros métodos de coleta não obtiveram um número importante de espécies, ainda que em alguns casos este tenha sido maior do que o observado no presente trabalho. Isso sugere que, embora essas famílias sejam pouco diversas, elas podem ter sido subamostradas no presente levantamento. A maior discrepância refere-se a Theridiosomatidae, cuja importância nos levantamentos foi, na maioria das vezes, bem maior do que a aqui observada.

De uma maneira geral, a hierarquia observada na distribuição da riqueza das famílias (Tabela 5) é mantida, embora no Morro Grande e região os dados mostrem uma maior dominância de duas famílias, em detrimento das demais. Mysmenidae e Uloboridae têm uma participação muito menor em Morro Grande e região do que a observada nos outros levantamentos. No entanto, esse fato pode ser decorrente da metodologia empregada, principalmente no que diz respeito à Mysmenidae. Em Linhares (ES) (Santos 1999) a família foi capturada exclusivamente pelo método do guardachuva entomológico, e no levantamento feito por Silva (1996), coletas diurnas através de procura ativa proporcionaram mais indivíduos e espécies do que as realizadas à noite, com o mesmo método. Por outro lado, a família esteve ausente na Cantareira (Pinto-da-Rocha, dados não publicados), apesar de terem sido empregados vários métodos de coleta, inclusive o guarda-chuva entomológico. Esse trabalho também contou com uma participação muito pequena de Uloboridae (0,5\%) e uma grande dominância de Araneidae (90,7\%), apresentando um padrão muito semelhante ao observado no presente levantamento. Esses levantamentos parecem indicar que a participação dessas famílias na região pode ser menos importante do que o observado nas áreas da Amazônia (Silva 1996, Silva \& Coddington 1996) e no Espírito Santo (Santos 1999).

Os três gêneros mais ricos encontrados no presente levantamento, todos da família Araneidae, parecem ser importantes componentes da guilda das orbitelas, uma vez que apresentaram a maior riqueza nos três outros levantamentos realizados na Mata Atlântica (Santos 1999, Brescovit et al. 2004b, Pinto-da-Rocha, dados não publicados) e também em um realizado em uma área de mata estacional decidual, no Rio Grande do Sul (Indrusiak \& Kotzian 1998). Os gêneros Alpaida e principalmente Micrathena também têm uma participação importante na riqueza em inventários amazônicos (Silva 1996, Silva \& Coddington 1996, Martins \& Lise 1997, Córdova \& Duarez 2001, Höfer \& Brescovit 2001), o que deve ser reflexo da riqueza total desses gêneros, bastante diversos (mais de 100 espécies). De maneira geral, a distribuição da abundância entre os gêneros acompanhou a da riqueza. Assim, Micrathena e Araneus foram os mais abundantes na Mata Atlântica (Santos 1999, Pinto-da-Rocha, dados não publicados) e Floresta Estacional Decidual (Indrusiak \& Kotzian 1998). O gênero Mangora (Araneidae) também esteve representado por um grande número de indivíduos na Cantareira (Pinto-da-Rocha, dados não publicados) e no presente levantamento, sendo que o último contou também com Chrysometa (Tetragnathidae) entre os mais abundantes. É interessante notar que esses quatro gêneros mencionados apresentam padrões diferentes de diversidade, tanto na Cantareira quanto no Morro Grande e região. Em Araneus e Chrysometa a abundância está dividida de forma mais eqüitativa entre as espécies, sendo que as mais abundantes representaram 25,9\% (Morro Grande e região) e 31,8\% (Cantareira) do total de indivíduos no caso de Araneus, e 31,6\% para Chrysometa (Morro Grande e região). Já Micrathena e Mangora, devem seu grande número de indivíduos a apenas uma ou duas espécies, que inclusive foram as mesmas nos dois levantamentos. Micrathena nigrichelis foi a aranha orbitela mais abundante nos dois levantamentos. M. guanabara foi a segunda mais numerosa em Morro Grande e região mas esteve ausente na Cantareira. A espécie Mangora sp.2, concentrou 75\% dos indivíduos do gênero em Morro Grande e região e 94\% na Cantareira.

A semelhança entre as faunas de orbitelas foi inversamente proporcional à distância entre as áreas, uma 
vez que houve 32 espécies compartilhadas com a Cantareira (Pinto-da-Rocha, dados não publicados), 12 com a Juréia (Brescovit et al. 2004b) e sete com Linhares (Santos 1999). No entanto, é importante mencionar que não houve comparação entre as morfoespécies desses inventários, de maneira que o total de espécies em comum entre elas pode ser maior.

\section{Diferenças entre os dois tipos de mata}

Os resultados indicam que a composição da comunidade de orbitelas difere entre os dois estádios de desenvolvimento da mata. Talvez o fator determinante seja a estrutura da vegetação, cuja importância para as orbitelas e araneofauna em geral já foi observada em outros trabalhos (Rypstra 1986, Wise 1993, Borges \& Brescovit 1996, Foelix 1996, Toti et al. 2000, Raizer \& Amaral 2004). Contudo, é preciso considerar que matas maduras e secundárias apresentam diferenças em outros aspectos, como o microclima e a diversidade de microhabitats (DeWalt et al. 2003).

As comunidades encontradas nos dois tipos de mata (Tabela 3) não parecem diferir em algum aspecto funcional, como o tamanho dos animais. A composição em níveis taxonômicos superiores também parece bastante homogênea, uma vez que vários gêneros apresentaram espécies associadas aos dois tipos de mata, como Araneus, Micrathena ou Chrysometa. Dessa maneira, as diferenças observadas parecem realmente ocorrer no nível específico, e podem estar relacionadas com aspectos da história de vida de cada espécie.

No entanto, a análise dos resultados esbarra na ausência quase total de estudos sobre a biologia desses animais, dificultando a avaliação da lista (Tabela 3). O inventário realizado na Cantareira (Pinto-da-Rocha, dados não publicados) parece ser a melhor, senão a única possibilidade de comparação com os resultados obtidos, uma vez que, além da composição da fauna ser muito semelhante, também amostrou áreas com diferentes graus de perturbação, embora sem realizar réplicas. A resposta de muitas espécies variou entre essas duas áreas, apresentando em alguns casos comportamento oposto. Verrucosa sp.1 teve o dobro de indivíduos em matas maduras na Cantareira, o inverso do que ocorreu em Morro Grande e região. Já Micrathena nigrichelis, por outro lado, exibiu comportamento contrário. Apenas as espécies Araneus iguacu, Chrysometa cambara e Testudinaria

estiveram associadas a matas mais maduras em ambas localidades, e Araneus orgaos foi a única a ocorrer preferencialmente em áreas secundárias nas duas áreas. É necessário ressaltar que o pequeno número de espécies a apresentar comportamento semelhante nos dois casos se deve ao fato de que na Cantareira foi registrado um número bem menor de orbitelas (72 contra 121 em Morro Grande e região), e poucas delas exibiram uma resposta clara em relação ao tipo de mata, talvez porque as áreas desse projeto fossem mais homogêneas do que as do Morro Grande. No entanto, fica claro que a lista aqui apresentada precisa ser analisada com cautela, e novas pesquisas são necessárias para verificar se a distribuição destas espécies está realmente relacionada ao grau de desenvolvimento das matas.

\section{Conservação}

Os resultados obtidos mostram que as florestas da Reserva do Morro Grande e região abrigam uma fauna bastante rica e abundante de aranhas orbitelas, incluindo espécies raras e até algumas ainda não descritas. Taczanowskia striata (Araneidae), por exemplo, é escassamente representada em coleções aracnológicas (Levi 1996), o mesmo ocorrendo com Parawixia inopinata (Araneidae) (Levi 1992). Também foram coletados 26 indivíduos de Micrathena cicuta (Santos \& Gonzaga 2004). Symphytognatha carstica é uma espécie recentemente descrita (Brescovit et al. 2004a), e sua ocorrência em Morro Grande foi interessante por ser o primeiro exemplar do gênero capturado fora de cavernas no Brasil. A espécie Dolicognatha sp.1 (Tetragnathidae) provavelmente também é nova para a ciência, e deverá ser descrita em breve. O gênero Alpaida também pode conter outras espécies novas, uma vez que seis morfoespécies não puderam ser identificadas, apesar da existência de uma revisão recente (Levi 1988). Os gêneros Azilia (Tetragnathidae), Mangora e Chthonos (Theridiosomatidae) também podem conter espécies novas, embora seja necessário um exame mais detalhado do material.

Esses resultados mostram a grande diversidade do grupo estudado e indicam que mesmo para um grupo relativamente bem conhecido como as aranhas orbitelas, o nosso conhecimento é ainda muito deficiente, o que evidencia a necessidade da manutenção das áreas de conservação existentes e, se possível, a criação de novas áreas. A importância da Reserva do Morro Grande como área de conservação também pode ser ressaltada por outros fatores. Além de ser uma das poucas (e uma das maiores) áreas de preservação da Mata Atlântica do interior de São Paulo, ela possui trechos de mata mais madura, o que permite a manutenção de uma comunidade de orbitelas característica, não encontrada em áreas de vegetação secundária.

\section{Agradecimentos}

Gostaríamos de agradecer ao Prof. Dr. Jean Paul Metzger e aos membros do Lepac, por disponibilizarem mapas e informações sobre as áreas amostradas. Agradecemos também ao José Roberto Nali, administrador da unidade da Sabesp de Alto Cotia, responsável pela Reserva, assim como aos demais funcionários. Agradecemos a todas as pessoas que ajudaram no campo durante as coletas. Agradecemos aos membros do LAL pela ajuda em diversas etapas do trabalho. Também somos gratos a dois 
revisores anônimos, pelas interessantes e úteis sugestões a esse trabalho. Por fim, o primeiro autor agradece à Capes, pela bolsa de mestrado concedida, e o terceiro autor ao CNPq. Este trabalho fez parte dos projetos temáticos BIOTA/ FAPESP "Biodiversidade de Arachnida e Myriapoda do estado de São Paulo” (processo 99/05546-) e “Conservação da Biodiversidade em Paisagens Fragmentadas no Planalto Atlântico de São Paulo” (processo 99/05123-4).

\section{Referências bibliográficas}

ABRAHAM, B.J. 1983. Spatial and temporal patterns in a sagebrush steppe spider community (ArachnidaAraneae). J. Arachnol. 11:31-50.

BLANCO-VARGAS, E., AMAT-GARCIA, G.D. \& FLOREZDÁZA, E. 2003. Araneofauna orbitelar (Araneae: Orbiculariae) de los Andes de Colombia: comunidades en habitats bajo regeneración. Revta Iber. Aracnol. 7:189-203.

BORGES, S.H. \& BRESCOVIT, A.D. 1996. Inventário preliminar da aracnofauna (Araneae) de duas localidades na Amazônia ocidental. Bolm Mus. paraense Emílio Goeldi, sér. Zool. 12:9-21.

BRESCOVIT, A.D., ÁLVARES, E.S.S. \& FERREIRA, R.L. 2004a. Two new species of Symphytognatha Hickman (Araneae, Symphytognathidae) from Brazil. Revta. Ibér. Aracnol. 10:75-80.

BRESCOVIT,A.D., BERTANI, R., PINTO-DA-ROCHA, R. \& RHEIMS, C.A. 2004b. Aracnídeos da Estação Ecológica Juréia -Itatins: inventário preliminar e história natural. In Estação Ecológica Juréia-Itatins: Ambiente físico, flora e fauna (O.A.V. Marques \& W. Duleba, eds.). Holos, Ribeirão Preto, p.198-221.

BÜCHERL, W. 1949. Em torno das três espécies insulares e praianas do gênero Pamphobeteus Pocock, 1901 (Mygalomorphae). Mem. Inst. Butantan. 21:117-136.

CHURCHILL, T.B. 1997. Spiders as ecological indicators: an overview for Australia. Mem. Mus. Vict. 56:331-337.

CHURCHILL, T.B. \& ARTHUR, J.M. 1999. Measuring spider richness: effects of diferent sampling methods and spatial and temporal scales. J. Insect Conserv. 3:287-295.

CODDINGTON, J.A. 1990. Cladistics and spider classification: araneomorph phylogeny and the monophyly of orbweavers (Araneae: Araneomorphae; Orbiculariae). Acta Zool. fenn. 197:75-87.

CODDINGTON, J.A., GRISWOLD, C.E., SILVA-DÁVILA, D., PEÑARANDA, E. \& LARCHER, S.F. 1991. Designing and testing sampling protocols to estimate biodiversity in tropical ecosystems. In The unity of evolutionary biology: proceedings of the Fourth International Congress of Systematic and Evolutionary Biology (E.C. Dudley, ed.). Dioscorides Press, Portland, p.44-60.

CODDINGTON, J.A., L.H. YOUNG \& COYLE, F.A. 1996. Estimating spider species richness in a southern Appalachian cove hardwood forest. J. Arachnol. 24:111-128.
COLWELL, R.K. 1997. EstimateS: Statistical estimation of species richness and shared species from samples. Version 5. User's guide and application published at: http// viceroy.eeb.uconn.edu/estimates.

CÓRDOVA, S. \& DUAREZ, J. 2001. Diversity and community structure of the spiders of the Lower Urubamba Region, Peru. In Urubamba: the biodiversity of a Peruvian Rainforest (A. Alonso, F. Dallmeier \& P. Campbell, eds.). Smithsoniam Institution/MAB Series \#7, Washington, p.67-71.

DEWALT, S.J., MALIAKAL, S.K. \& DENSLOW, J.S. 2003. Changes in vegetation structure and composition along a tropical forest chronosequence: implications for wildlife. Forest. Ecol. Managem. 182:139-151.

DIPPENAAR-SCHOEMAN, A.S., VAN DEN BERG, A.M. \& VAN DEN BERG, A. 1989. Species composition and relative abundance of spiders from the field and tree layers of the Roodeplaat Dam Nature Reserve. Koede. 32:25-38.

DIPPENAAR-SCHOEMAN, A.S. \& JOCQUÉ, R. 1997. Africain spiders. An identification manual. Plant Protection Research Institute - Biosystematics Division, Pretoria.

FOELIX, R.F. 1996. Biology of spiders. Oxford University Press, Oxford.

FOWLER, H.G \& VENTICINQUE, E.M. 1995. Ground spider (Araneae) diversity in differing habitats in the Ilha do Cardoso State Park. Naturalia. 20:75-81.

HÖFER, H., BRESCOVIT, A.D., ADIS, J. \& PAARMANN, W. 1994. The spider fauna of neotropical tree canopies in Central Amazonia: first results. Studies Neotr. Fauna Envir. 29:23-32.

HÖFER, H. \& BRESCOVIT, A.D. 2001. Species and guild structure of a Neotropical spider assemblage (Araneae) from Reserva Ducke, Amazonas, Brazil. Andrias. 15:99-119.

INDRUSIAK, L.F. \& KOTZIAN, C.B. 1998. Inventário das aranhas arborícolas de três regiões da Santa Maria, RS, Brasil. Revta Ciênc. Nat, Santa Maria. 20:187-214.

KOVACH COMPUTING SERVICES. 2000. Multivariate statistical package: MVSP (Computer program mannual). Version 3.12b, KCS, UK.

LEVI, H.W. 1988. The neotropical orb-weaving spiders of the genus Alpaida (Araneae: Araneidae). Bull. Mus. comp. Zool. 151:365-487.

LEVI, H.W. 1992. Spiders of the orb-weaver genus Parawixia in America (Araneae: Araneidae). Bull. Mus. comp. Zool. 153:1-46.

LEVI, H.W. 1996. The genus Taczanowskia of the orbweaver spider family Araneidae (Araneae). An. Inst. Biol. Univ. Mex.. 67:183-195. 
LEVINGS, S.C. \& WINDSOR, D.M. 1984. Litter moisture content as a determinant of litter arthropod distribution and abundance during the dry season on Barro Colorado Island, Panama. Biotropica. 16:125-131.

LISE, A.A. 1998. Notes on the spiders of the Ilha de Maracá. In Maracá: The biodiversity and environment of an Amazonian rainforest (W. Milliken \& J.A. Ratter, eds.). John Wiley \& Sons, Chichester, p.377-380.

LUBIN, Y. 1978. Seasonal abundance and diversity of webbuilding spiders in relation to habitat structure on Barro Colorado Island, Panama. J. Arachnol. 6:31-51.

LUEDERWALDT, H. 1929. Resultados de uma excursão scientifica á Ilha de São Sebastião no littoral do Estado de São Paulo e em 1925. Revta Mus. paulista. 16:3-79.

MAGURRAN, A.E. 1988. Ecological diversity and its measurement. Princeton University Press, Princeton.

MAJADAS, A. \& URONES, C. 2002. Communauté d'araignées des maquis méditerranéens de Cytisus oromediterraneus Rivas Mart. \& al. Revue Arachnol. 14:31-48.

MARTINS, M. \& LISE, A. 1997. As aranhas. In Caxiuanã (P.L.B. Lisboa, org.). Museu Paraense Emílio Goeldi, Belém, p.381-388.

MELLO-LEITÃO, C.F. 1923. Arachnideos da Ilha de Alcatrazes. Revta Mus. paulista. 12:3-8.

METZGER, J.P.,ALVES,L.A., CATHARINO,E.L.M., GOULART \&W., SIMÕES, S.J.C. 2006. Uma área de relevante interesse biológico, porém pouco conhecida: a Reserva Florestal do Morro Grande. Biota Neotrop. 6(2): http:// w w w.biotaneotropica.org.br/v6n2/pt/ abstract?article+bn00406022006 (últimoacessoem03/05/2006).

NENTWIG, W. 1989. Seasonal and taxonomic aspects of the size of arthorpods in the tropics and its possible influence on size-selectivity in the prey of a tropical spider community. Oecologia. 78:35-40.

NEW, T.R. 1999. Untangling the web: spiders and the challenges of invertebrate conservation. J. Insect Conserv. 3:251-256.

NORRIS, K.C. 1999. Quantifying change through time in spider assemblages: sampling methods, indices and sources of error. J. Insect Conserv. 3:309-325.

NYFFELER, M., STERLING W.L. \& DEAN, D.A. 1994. How spiders make a living. Env. Ent. 23:1357-1367.

PLATNICK, N.I. 2006. The world spider catalog, version 6.5. American Museum of Natural History online at http://research.amnh.org/entomology/spiders/catalog/ index.html

RAIZER, J. \& AMARAL, M.E. 2004. Does the structural complexity of aquatic macrophytes explain the diversity of associated spider assemblages? J. Arachnol. 29:227-237.

RYPSTRA, A.L. 1986. Web spiders in temperate an tropical forests: relative abundance an environmental correlates. Am. Mid. Nat. 115:42-51.
SANTOS, A.J. 1999. Diversidade e composição em espécies de aranhas da Reserva Florestal da Companhia Vale do Rio Doce (Linhares - ES). Dissertação de mestrado. Universidade Estadual de Campinas, Campinas.

SANTOS, A. J. 2003. Estimativas de Riqueza em Espécies. In Métodos de Estudos em Biologia da Conservação e Manejo da Vida Silvestre (L. Cullen Jr., R. Rudran \& C. Valladares-Pádua, orgs.). Editora da UFPR - Fundação o Boticário de Proteção à Natureza, Curitiba, p.19-41.

SANTOS, A. J. \& GONZAGA, M. O.A. 2004. New species and a new synonymy in the spiny orb-weaver genus Micrathena (Araneae, Araneidae). J. Arachnol. 32:332-335.

SCHARFF, N., CODDINGTON, J.A., GRISWOLD, C.E., HORMIGA, G. \& BJORN, P.D.P. 2003. When to quit? Estimating spider species richness in a northern European deciduos forest. J. Arachnol. 31:246-273.

SILVA, D. 1996. Species composition and community structure of Peruvian rainforest spiders: a case study from a seasonally inundated forest along the Samiria river. Revue suisse Zool. 1:597-610.

SILVA, D. \& CODDINGTON, J.A. 1996. Spiders of Pakitza (Madre de Dios, Perú): species richness and notes on community structure. In Manu-The biodiversity of Southeastern Perú (D.E. Wilson \& A. Sandoval, eds.). Smithsonian Institution Press, Washington, p.253-311.

SORENSEN, L.L., CODDINGTON, J.A. \& SCHARFF, N. 2002. Inventorying and estimating sub-canopy spider diversity using semi-quantitative sampling methods in an Afromontane forest. Env. Ent. 31:319-330.

TOTI, D.S., COYLE, F.A. \& MILLER, J.A. 2000. A structured inventory of Appalachian grass bald and heath bald spider asemlages and a test of species richness estimator performance. J. Arachnol. 28:329-345.

UETZ, G.W., HALAJ, J. \& CADY, A.B. 1999. Guild structure of spiders in major crops. J. Arachnol. 27:270-280.

WISE, D.H. 1993. Spiders in ecological webs. Cambridge University Press, Cambridge.

Título: Comunidade de aranhas orbitelas (ArachnidaAraneae) na região da Reserva Florestal do Morro Grande, Cotia, São Paulo, Brasil.

Autores: Nogueira, A. A.; Pinto-da-Rocha, R.; Brescovit, A. D.

Biota Neotropica, Vol.6 ( número 2 ): 2006 http://www.biotaneotropica.org.br/v6n2/pt/ abstract?article+bn00906022006

Recebido em 11/3/2004 - Versão reformulada recebida em 21/3/2005 - Publicado em 01/05/2006

ISSN 1676-0603 


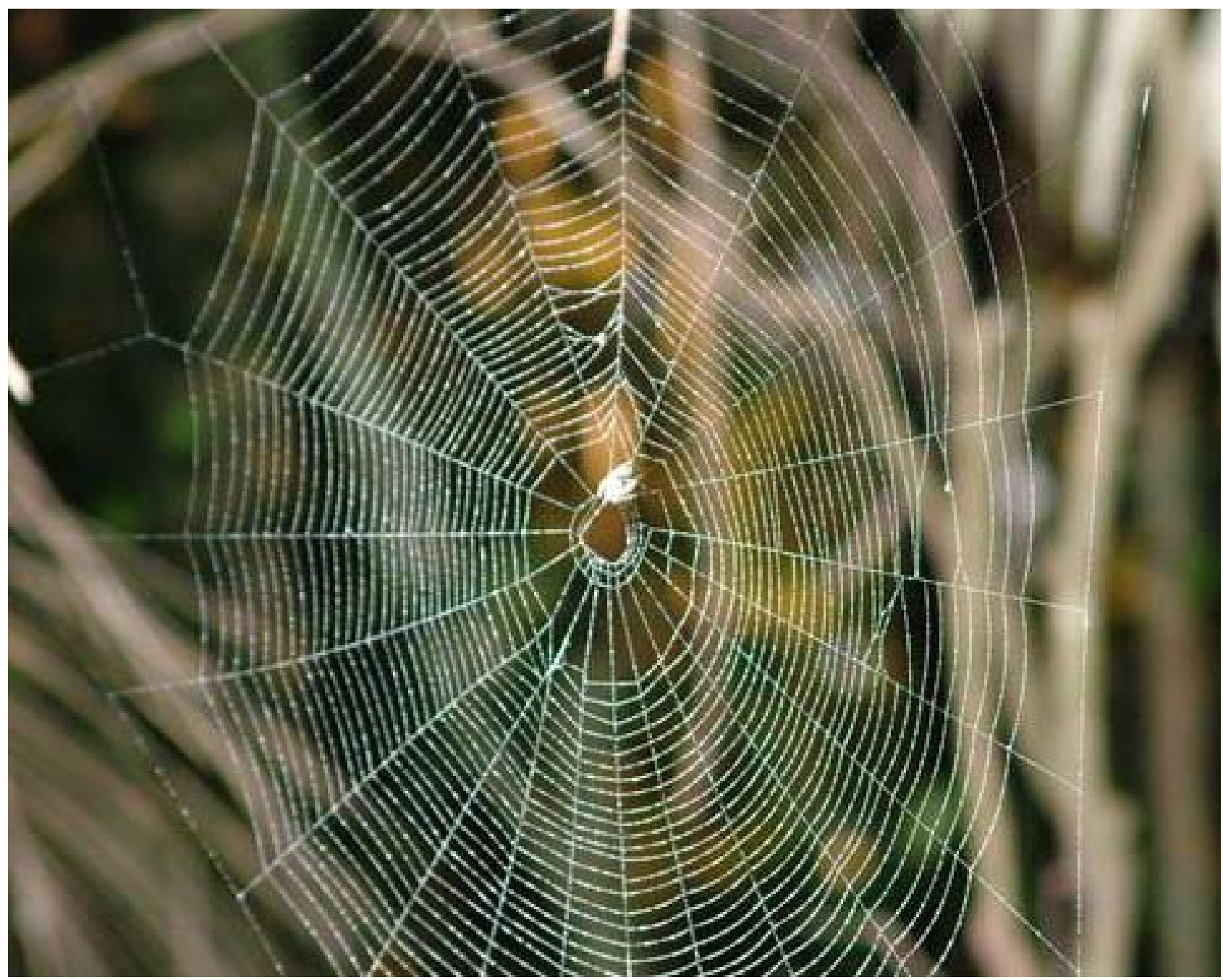

Figura 1. Teia orbicular de Parawixia sp. (Araneidae), jovem. Foto: Lia Monguilhott.

Figure 1 - Orb-web of an immature Parawixia (Araneidae). Photo: Lia Monguilhott. 


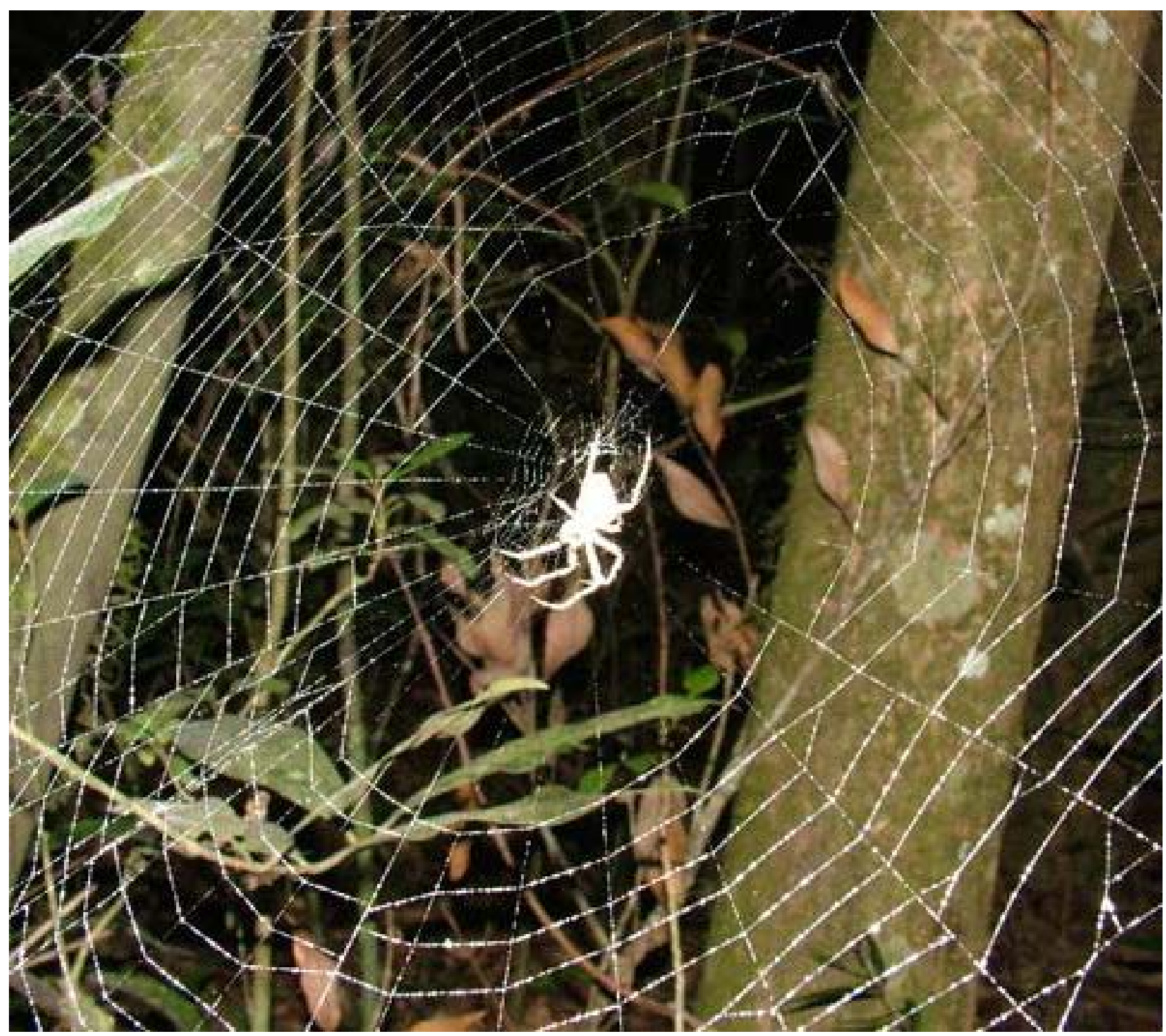

Figura 2. Detalhe da região central da teia orbicular de Parawia sp. (Araneidae), jovem. Foto: Alexandre Albuquerque da Silva. Figure 2 - Close-up of the orb web of an immature Parawixia (Araneidae). Photo: Alexandre Albuquerque da Silva. 


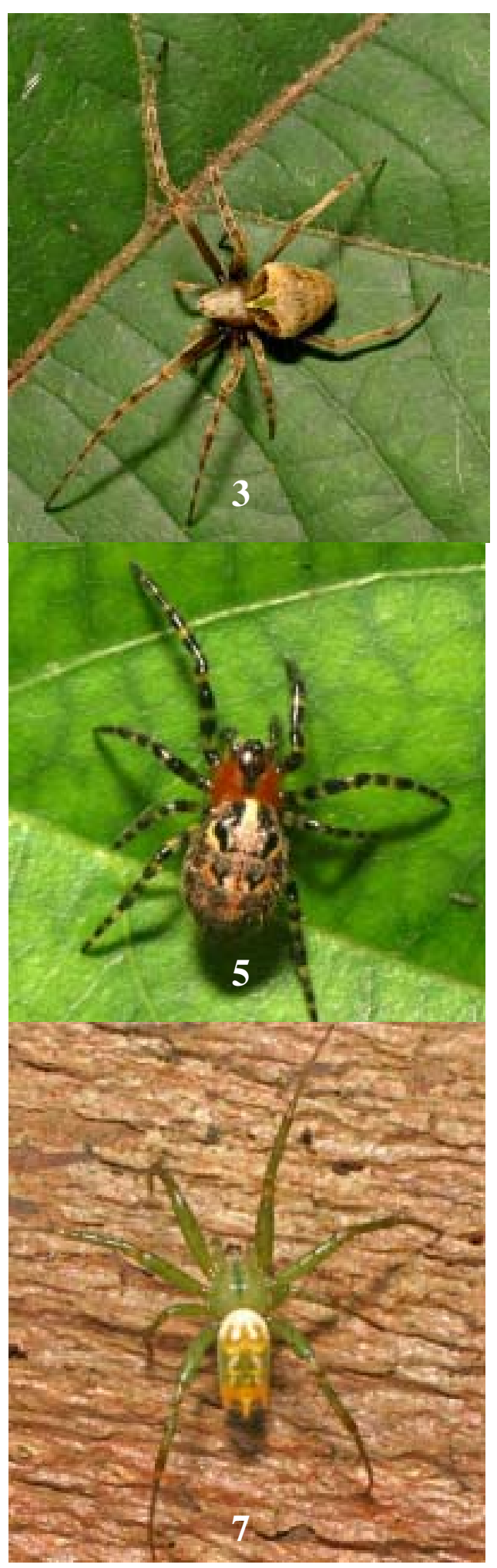

Figuras 3-8. Aranhas orbitelas de Morro Grande e região. 3, fêmea de Acacesia sp., ; 4, fêmea de Araneus iguacu guardando a ooteca; 5, fêmea de Alpaida sp.; 6, fêmea de Micrathena guanabara, a segunda espécie mais abundante deste inventário; 7, fêmea de Mangora sp.2, a terceira espécie mais abundante; 8, macho de de Mangora sp.2 em vista ventral, é possível observar os bulbos copulatórios bem desenvolvidos. Fotos: Henrique Marianno.

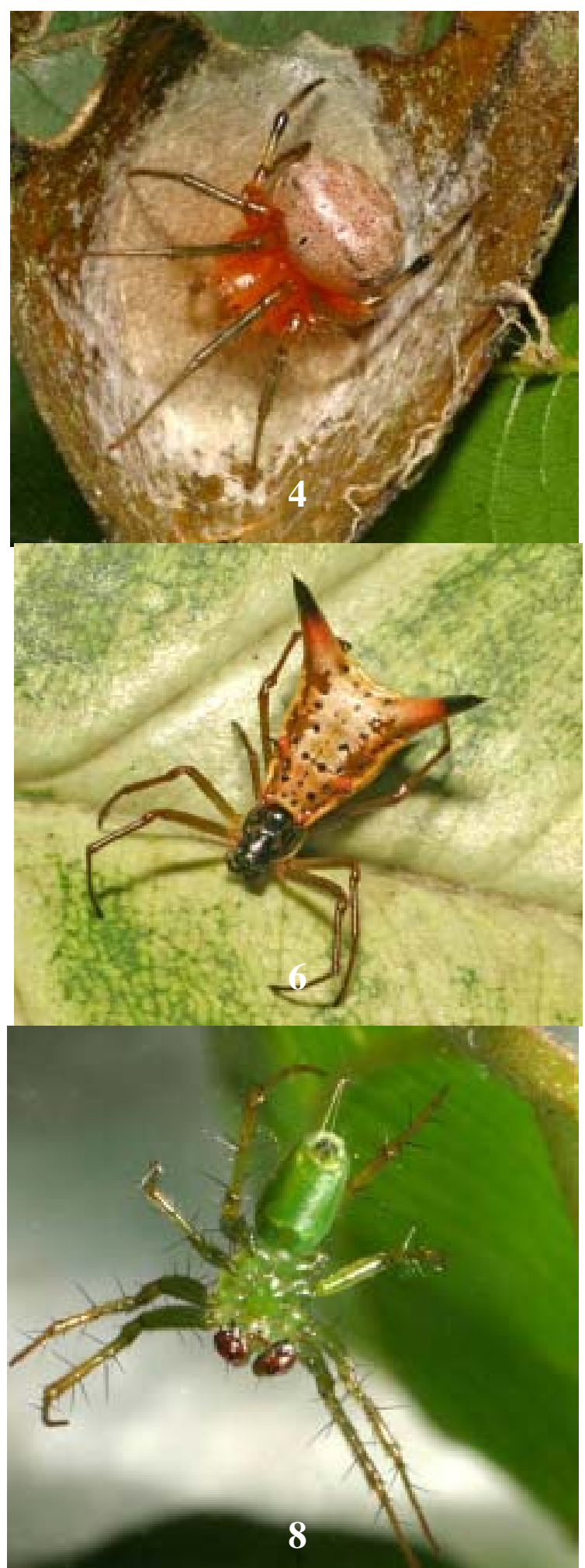

Figures 3-8 - Orb-weaver species from Reserva Florestal do Morro Grande and surrounding areas. 3, Acacesia sp., female; 4, Araneus iguacu, female with cocoon; 5, Alpaida sp., immature; 6 Micrathena guanabara, female; 7, Mangora sp.2, female, the third most abundant species in our inventory; 8, Mangora sp.2, ventral view of a male specimen, with it's well developed copulatory palps. Photos: Henrique Marianno. 


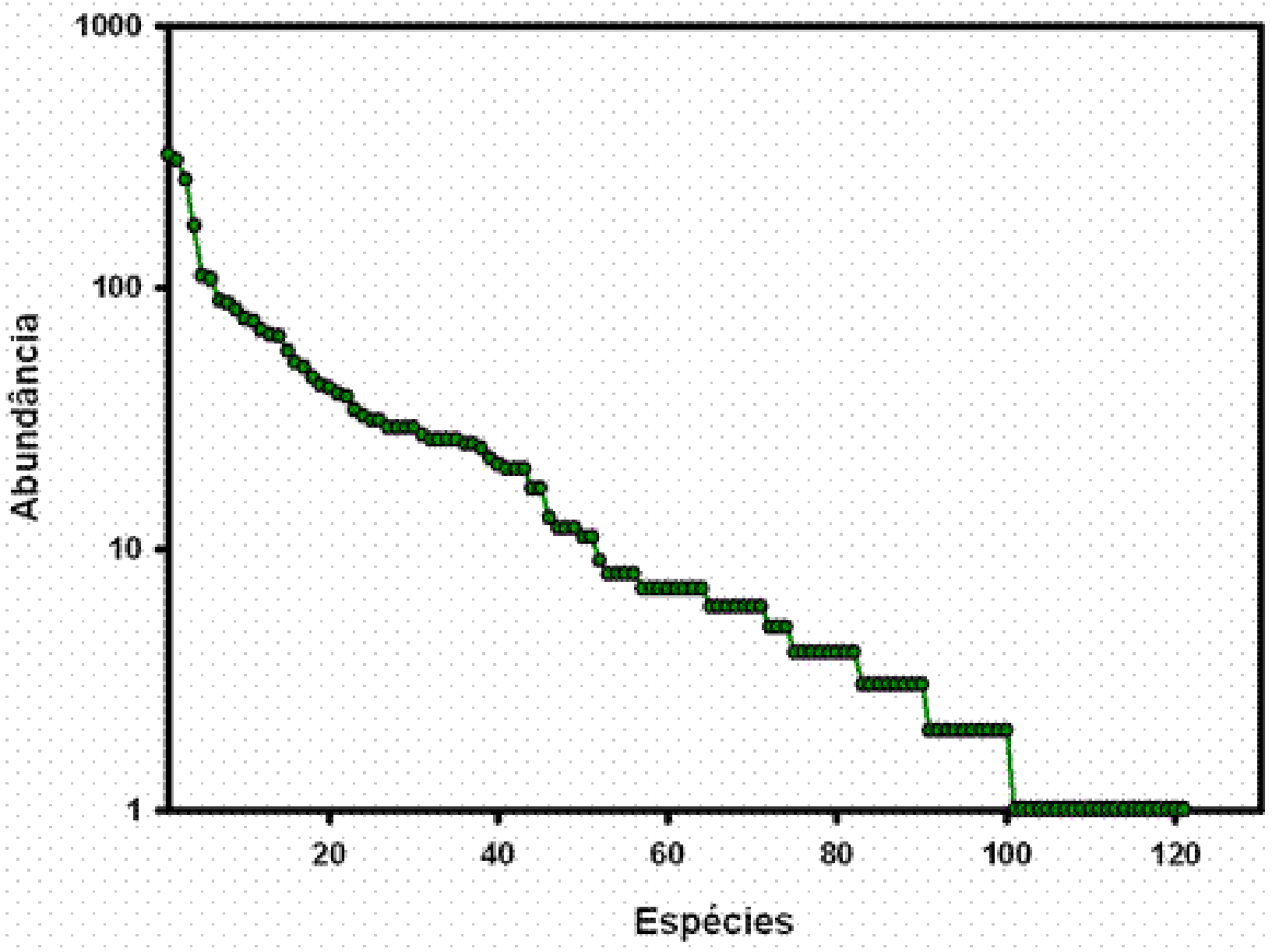

Figura 9 - Curva de abundância da comunidade de aranhas orbitelas de Morro Grande e região, referentes aos meses de dezembro/2002 e março/2003. Eixo y em escala logarítmica.

Figure 9 - Rank abundance diagram for the orb-weaver spiders collected at Reserva Florestal do Morro Grande and surrounding areas, in December/2002 and March/2003. 


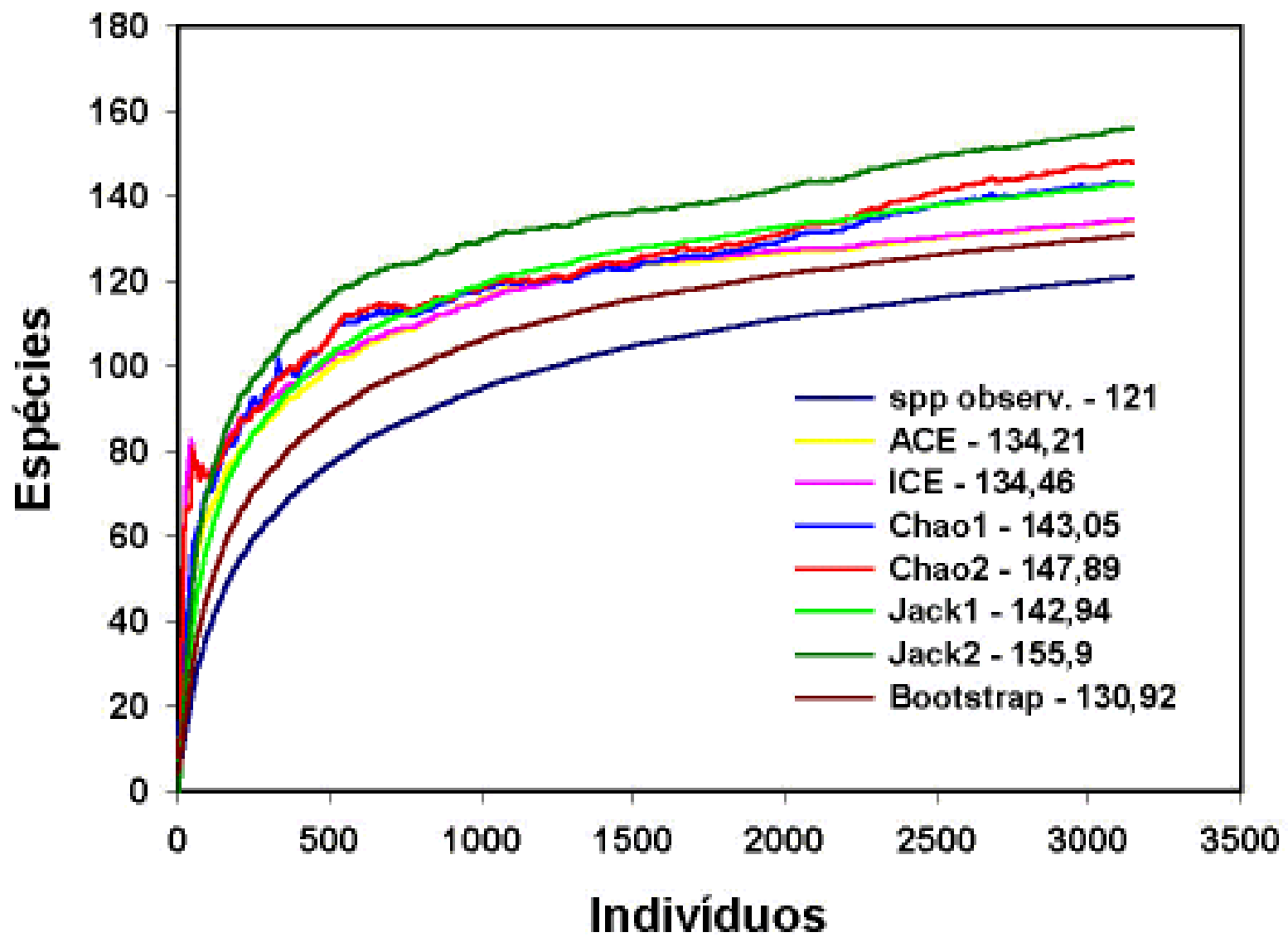

Figura 10 - Riqueza observada e estimativas de riqueza da comunidade de aranhas orbitelas de Morro Grande e região, nos meses de dezembro/2002 e março/2003.

Figure 10 - Observed richness and richness estimator curves for the orb-weaver spider community from Reserva Florestal do Morro Grande and surrounding areas, collected in December/2002 and March/2003. 


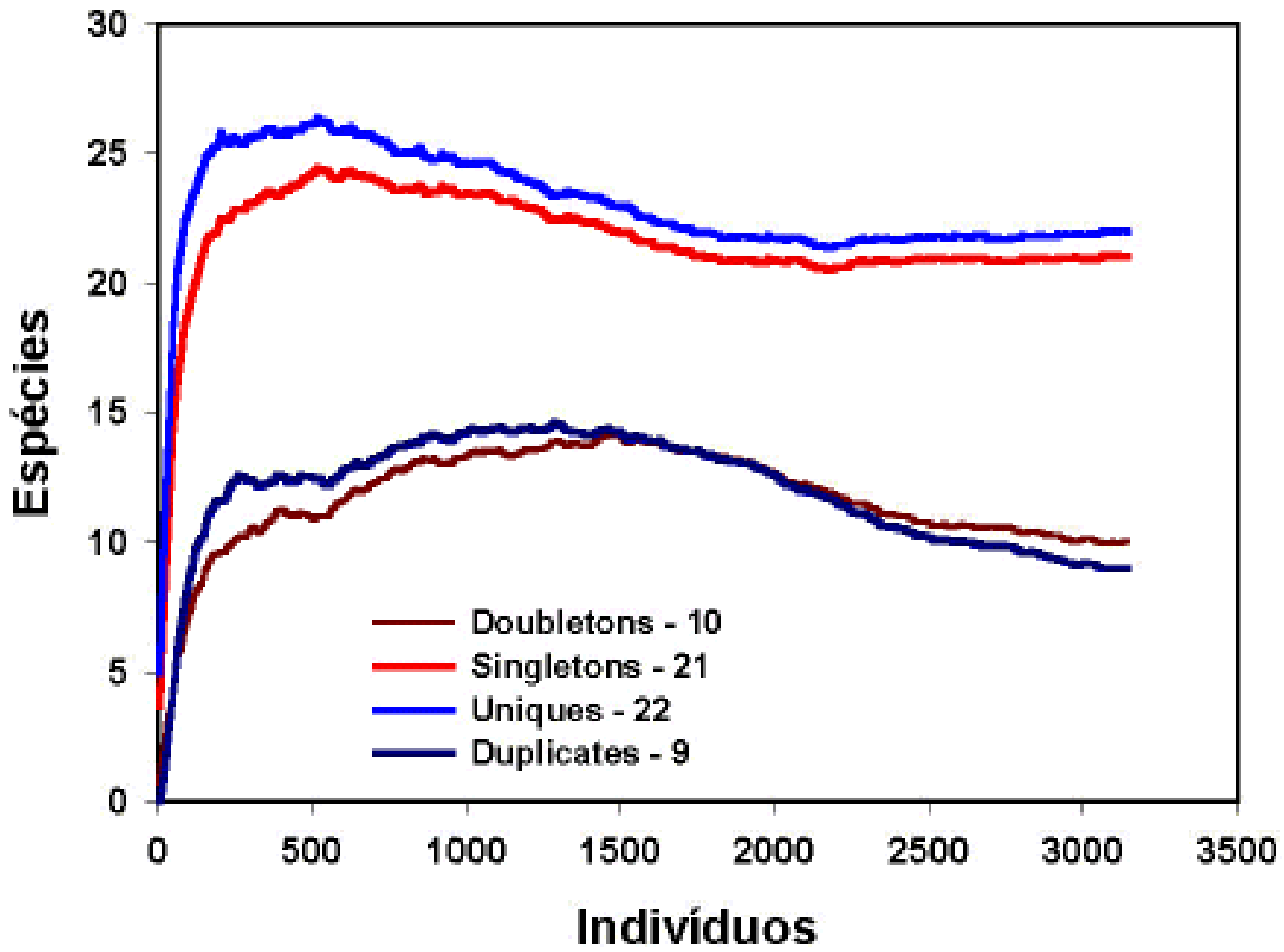

Figura 11 - Espécies raras da comunidade de aranhas orbitelas de Morro Grande e região, nos meses de dezembro/2002 e março/2003. Figure 11 - Curves for rare orb-weaver species from Reserva Florestal do Morro Grande and surrounding areas, collected in December/2002 and March/2003. 


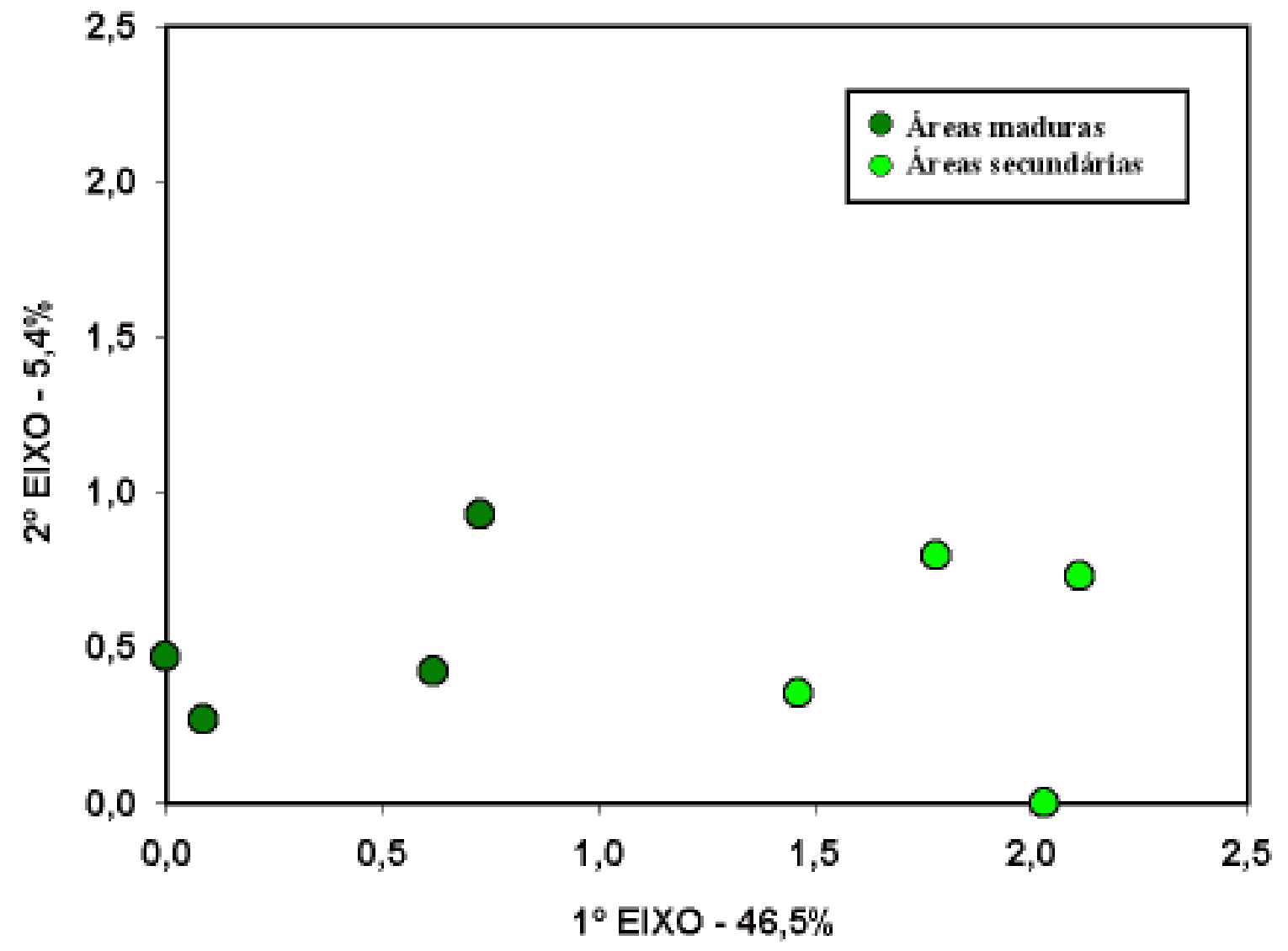

Figura 12 - DCA da comunidade de aranhas orbitelas das oito áreas da Reserva Morro Grande (Cotia-SP); nos meses de dezembro/2002 e março/2003.

Figure 12 - DCA of the orb-weaver spider community from the eight areas sampled in the Reserva Florestal do Morro Grande, in December/ 2002 and March/2003. 
Tabela 1. Riqueza e abundância das famílias de aranhas orbitelas coletadas em Morro Grande e região, nos meses de dezembro/2002 e março/2003.

Table 1 - Richness and abundance of orb-weaver spiders collected in Morro Grande and surroundings areas, in December/02 and March/03

\begin{tabular}{lccc}
\hline Família & Spp & Adultos & Jovens \\
\hline Araneidae & 76 & 2.225 & 8.163 \\
Tetragnathidae & 26 & 674 & 1.232 \\
Theridiosomatidae & 9 & 167 & 4 \\
Uloboridae & 6 & 62 & 135 \\
Anapidae & 2 & 12 & 0 \\
Mysmenidae & 1 & 7 & 1 \\
Symphytognathidae & 1 & 1 & 0 \\
& & & \\
Total & 121 & 3.148 & 9.535 \\
\hline
\end{tabular}

http://www.biotaneotropica.org.br 
Tabela 2. Abundância de aranhas orbitelas coletadas na Reserva do Morro Grande (Cotia-SP) e em fragmentos florestais da região vizinha (Cotia e Ibiúna-SP), em dezembro/2002 e março/2003.

Table 2 - Abundance of orb-weaver spider species collected at Reseva Florestal do Morro Grande (Cotia-SP) and nearby forest fragments (Cotia and Ibiúna-SP), in December/02 and March/03.

\begin{tabular}{|c|c|c|c|c|c|c|c|c|c|c|c|c|c|c|c|c|c|}
\hline \multirow[b]{2}{*}{ Espécie } & \multicolumn{8}{|c|}{ Morro Grande } & \multicolumn{8}{|c|}{ Fragmentos } & \multirow[b]{2}{*}{$\underset{1}{\overline{\mathbb{T}}}$} \\
\hline & 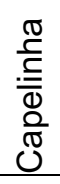 & $\begin{array}{l}\text { 을 } \\
\frac{0}{0} \\
\frac{\bar{Z}}{0} \\
0\end{array}$ & 哭 & 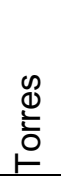 & $\begin{array}{l}\varangle \\
\mathbb{ఠ} \\
\Phi \\
\frac{1}{<}\end{array}$ & $\begin{array}{l}\infty \\
\mathbb{\Xi} \\
\stackrel{d}{<} \\
\end{array}$ & $\begin{array}{l}0 \\
\mathbb{ల} \\
\mathbb{d} \\
.<\end{array}$ & 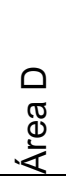 & $\stackrel{\text { o }}{\stackrel{\text { o }}{\Sigma}}$ & $\begin{array}{l}\text { 요 } \\
\text { ô } \\
\text { 음 } \\
0 \\
0\end{array}$ & $\begin{array}{l}\text { 음 } \\
\text { d } \\
\text { 口. }\end{array}$ & 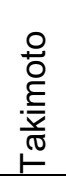 & 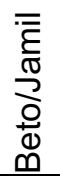 & 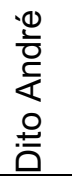 & $\frac{\sigma}{\bar{\perp}}$ & $\begin{array}{l}\frac{0}{0} \\
\frac{0}{0} \\
0 \\
\text { ত }\end{array}$ & \\
\hline \multicolumn{18}{|l|}{ Anapidae } \\
\hline Pseudanapis sp.1 & 2 & 1 & & & & 1 & & 2 & & & & & & & & & 6 \\
\hline Pseudanapis sp.2 & 3 & 1 & 1 & & & & & & & & & & & & 1 & & 6 \\
\hline \multicolumn{18}{|l|}{ Araneidae } \\
\hline Acacesia corniger & & & 1 & & & & & & 2 & & & & & & & & 3 \\
\hline Acacesia graciosa & & & & & & 1 & 6 & & 5 & 1 & 5 & 1 & 3 & 1 & 1 & 2 & 26 \\
\hline Acacesia villalobosi & & 1 & 2 & 1 & & & & & & & & & 3 & & & & 7 \\
\hline Acacesia yacuiensis & & & & & 3 & & & & & 1 & & & 1 & 1 & & & 6 \\
\hline Acacesia sp.1 & 2 & & 1 & & 1 & 2 & 3 & 5 & 8 & & 1 & 7 & 1 & 4 & 1 & 3 & 39 \\
\hline Alpaida alticeps & & & & & & & 1 & & 1 & 2 & 1 & 1 & & 1 & & & 7 \\
\hline Alpaida atomaria & & & & & & & & & & & 1 & & 1 & 1 & & & 3 \\
\hline Alpaida hoffmani & & & & & 3 & 3 & 2 & & & & & & & & & & 8 \\
\hline Alpaida lanei & & & & & & & & & & 2 & & & & 1 & & & 3 \\
\hline Alpaida pedro & 2 & 3 & 1 & 5 & 1 & 3 & & 5 & 1 & & & 1 & & 2 & 4 & 1 & 29 \\
\hline Alpaida scriba & & 1 & & & 6 & 15 & & 3 & & 3 & 2 & 3 & 1 & 2 & & 2 & 38 \\
\hline Alpaida tijuca & & & & 1 & & & 1 & 2 & & & & & 1 & & 2 & & 7 \\
\hline Alpaida truncata & & & & 1 & & & 1 & & 1 & & & & & & 1 & & 4 \\
\hline Alpaida aff. canela & 1 & & & & & & & & & & & & & & & & 1 \\
\hline Alpaida aff. canoa & & 2 & & & & 4 & & 5 & & & & & & & & & 11 \\
\hline Alpaida sp. 1 & 6 & 4 & 2 & & & & & & & & & & & & & & 12 \\
\hline Alpaida sp.2 & & & & & & 1 & & & & 1 & & & 1 & & & & 3 \\
\hline Alpaida sp. 3 & & & & & & & & & & & & & 2 & & & & 2 \\
\hline Alpaida sp.4 & & & & & & & & & & & & & & 1 & & 1 & 2 \\
\hline Alpaida sp. 5 & & & & & & & & & & & & & & 1 & & & 1 \\
\hline Alpaida sp. 6 & & & & & & & & & & & & & & 1 & & & 1 \\
\hline Araneus iguacu & 10 & 19 & 10 & & 1 & 6 & 2 & 4 & 4 & 5 & & 2 & & 11 & & & 74 \\
\hline Araneus omnicolor & 11 & 1 & 5 & 3 & 4 & 3 & 9 & 4 & 5 & 2 & 5 & 5 & 6 & 7 & 4 & 2 & 76 \\
\hline Araneus orgaos & 2 & 1 & 1 & 2 & 9 & 6 & 3 & 2 & 4 & & & 3 & 9 & 8 & 1 & & 51 \\
\hline Araneus stabilis & & & & & & & & & 3 & 1 & & 1 & 1 & 1 & & & 7 \\
\hline Araneus unanimus & & & & & & & & & & 1 & & & & & & & 1 \\
\hline Araneus uniformis & & & & & & & 1 & & & & & & & & & & 1 \\
\hline Araneus venatrix & 1 & 1 & & & & 1 & & & 6 & 3 & 4 & & 1 & 1 & 2 & & 20 \\
\hline Araneus vincibilis & 1 & & 1 & 2 & 2 & 3 & 2 & 8 & & & 3 & & 2 & 1 & 2 & 2 & 29 \\
\hline Araneus workmani & 1 & & & & & & & & & & & 1 & & & & & 2 \\
\hline Araneus sp.1 & 6 & & 1 & & 1 & 2 & 3 & 2 & 4 & & & 2 & 4 & 5 & 2 & & 32 \\
\hline Bertrana rufostriata & & & & & & & & & & 1 & & & & & & & 1 \\
\hline Bertrana sp.1 & 1 & & & & & & 1 & & & 1 & & & & & & & 3 \\
\hline Cyclosa camargoi & 1 & & 3 & 1 & & 1 & & & & 1 & & & & & & & 7 \\
\hline Cyclosa diversa & & & & & & 1 & & & & & & & & & & & 1 \\
\hline Cyclosa fililineata & 4 & 2 & 1 & & 5 & 7 & 3 & 8 & 1 & & 1 & & & 1 & & 1 & 34 \\
\hline Cyclosa morretes & 3 & & 3 & 2 & 7 & 5 & 1 & 1 & & 1 & 1 & & 4 & & 1 & & 29 \\
\hline
\end{tabular}

http://www.biotaneotropica.org.br 


\begin{tabular}{|c|c|c|c|c|c|c|c|c|c|c|c|c|c|c|c|c|c|}
\hline Cyclosa tapetifaciens & 1 & & & & & & & 2 & 1 & & & & & & & & \\
\hline Eriophora sp.1 & 1 & & & & 3 & 1 & 1 & 2 & 1 & & 6 & 2 & 3 & & 1 & 1 & 22 \\
\hline Eustala sp.1 & & & & & & & & & 1 & 1 & & & & & & & \\
\hline ustala sp.2 & & 1 & & & 3 & & 1 & 1 & & & & & & & & & \\
\hline ustala sp.3 & & & & & 1 & & 1 & & 1 & & 1 & & & & & & \\
\hline ustala sp.4 & & & & & 1 & & & & & & & & & & & & \\
\hline apogea alayoi & & & & & & & & & & & & & 1 & & & & \\
\hline langora sp.1 & & & & & 1 & 1 & 1 & 4 & & & & & & & & & \\
\hline ra sp.2 & 20 & 7 & 6 & 12 & 26 & 20 & 12 & 5 & 21 & 9 & 17 & 28 & 19 & 25 & 15 & 16 & 258 \\
\hline ra sp.3 & & & & & & & & & & & & & & & & 1 & \\
\hline langora sp.4 & & & & & & & & 1 & 3 & 3 & 1 & 3 & 2 & 5 & 1 & 1 & \\
\hline Mangora sp. 5 & 4 & 4 & 30 & 10 & & & & 4 & & & & & & & 5 & & \\
\hline Micrathena crassispina & & & 4 & 2 & 6 & 10 & 1 & 3 & 1 & 2 & 3 & 3 & 1 & & 5 & 1 & \\
\hline Micrathena guanak & 53 & 55 & 32 & 28 & 20 & 13 & 19 & 19 & 3 & 2 & 1 & 3 & 4 & 2 & 14 & 38 & 30 \\
\hline Micrathena jundiai & & & & & & & & & & & & & & 1 & 1 & & \\
\hline Micrathena nigrichelis & 59 & 10 & 109 & 82 & 2 & 1 & 1 & & 1 & & & & & 55 & & & 32 \\
\hline Micrathena spitzi & & 1 & & & 1 & & 1 & & 1 & & & & & & & & \\
\hline Aicrathe & 9 & 16 & 13 & & & & & & 3 & & & & & & & & \\
\hline Micrathe & 1 & & & & & 2 & 2 & 4 & 6 & & & 1 & & 6 & 3 & 1 & \\
\hline Ocre & & & & & & 3 & 1 & 1 & 4 & 4 & & 4 & 5 & 3 & . & & \\
\hline Dar & 1 & 2 & 1 & & & 2 & 2 & & & & & & & & & & \\
\hline ar & 3 & & & 1 & & & & & & & & & & & & & \\
\hline Para & & & & & 1 & & 1 & & 1 & & & 1 & & & & & \\
\hline $\operatorname{arc}$ & & & & & 1 & & & 2 & & & & & & & & & \\
\hline$a r$ & & & & & & & & & & & & & & & & 1 & \\
\hline Scoloder & & 1 & & & & & 1 & & & & & & & & 2 & & \\
\hline Scolode & & & & & & & & & & & & & & & 1 & 1 & \\
\hline Taczano & & & 1 & 1 & & & 1 & & & & & & 1 & & & & \\
\hline Tatepeir & & & & & 2 & 1 & & 2 & 1 & & & & & & & & \\
\hline Testudin & 11 & 11 & 4 & 13 & & 1 & & 6 & 3 & 11 & & & 1 & 4 & 1 & & \\
\hline Testudinaria ler & 2 & & & 1 & & 2 & & 4 & 8 & 7 & 8 & 6 & 8 & 4 & 12 & 6 & \\
\hline Testudinaria un & & & & & & & & & & & & & & 2 & & 1 & \\
\hline Testudinaria bo & & 1 & & & & & & & 1 & 1 & & & 1 & 1 & & 1 & \\
\hline Verrucc & & & & & & & & & & 1 & & & & & & & \\
\hline Verruco & & & & & & & & 1 & & & & & & & & & \\
\hline Ver & 3 & 5 & 4 & & 14 & 15 & 3 & 3 & 7 & 6 & 5 & 2 & 2 & 3 & 5 & 5 & \\
\hline $\mathrm{Na}$ & 8 & 11 & 10 & 5 & 1 & 2 & 2 & 3 & 1 & 1 & 1 & 2 & & 1 & & 1 & \\
\hline Nag & 1 & 1 & & & 26 & 18 & 5 & 10 & 10 & 12 & 7 & 20 & 26 & 19 & 4 & 12 & 17 \\
\hline Nagneria & & & & 2 & 2 & 1 & 1 & 4 & & & & 1 & & & & & \\
\hline lysmen & & & & & & & & & & & & & & & & & \\
\hline Mysmenidae sp.1 & 1 & & & & & & & & & 1 & & 2 & & & & 3 & \\
\hline mnherngthi & & & & & & & & & & & & & & & & & \\
\hline Symphytognatha sp. 1 & & r & & & & & & & & & & & & & & & \\
\hline etragnathidae & & & & & & & & & & & & & & & & & \\
\hline Azilia histrio & 4 & 10 & 6 & 4 & & 2 & 1 & 8 & 1 & 3 & 1 & & 1 & 1 & 1 & 2 & \\
\hline Azilia sp.1 & & & & & & 3 & 1 & 6 & & 1 & 2 & & & 2 & & 2 & \\
\hline Azilia sp.2 & 2 & J & 1 & & & & & & & & & & & & & 1 & \\
\hline Azilia sp. 3 & 7 & 8 & & & & & 2 & 3 & & & & & & & & & \\
\hline zilia sp.4 & & & $T$ & & & & & & & & & & & & & & \\
\hline zilia sp.5 & & 1 & & & & & & & & & & & & & & & \\
\hline Chrysometa boraceia & 10 & 20 & 3 & 4 & 9 & 6 & & 9 & 1 & & & 2 & & 1 & & & \\
\hline
\end{tabular}


Chrysometa cambara

Chrysometa itaimba

Chrysometa ludibunda

Chrysometa sumare

Chrysometa sp.1

Cyrtognatha sp.1

Diphya bicolor

Dolicognatha pinheiral

Dolicognatha sp.1

Homalometa sp.1

Homalometa sp. 2

Leucauge sp. 1

Leucauge sp.2

Leucauge sp. 3

Leucauge sp.4

Nephila clavipes

Tetragnatha sp. 1

Tetragnathidae sp. 1

Tetragnathidae sp. 2

Theridiosomatidae

Chthonos sp. 1

Chthonos sp.2

Chthonos sp. 3

Ogulnius sp.1

Ogulnius sp. 2

Theridiosomatidae sp.1

Theridiosomatidae sp. 2

Theridiosomatidae sp. 3

Theridiosomatidae sp.4

Uloboridae

Miagrammopes sp. 1

Miagrammopes sp. 2

Miagrammopes sp. 3

Philoponella sp. 1

Uloborus penicillatus

Uloboridae sp.1 $\begin{array}{llll}1 & 2 & 10 & 12\end{array}$

$\begin{array}{llll}2 & 8 & 4 & 3\end{array}$

$\begin{array}{llllllll}11 & 22 & 13 & 39 & 1 & 5 & 10 & 1\end{array}$

$\begin{array}{ll}9 & 1\end{array}$

25

112023

210

$\begin{array}{lll}4 & 1\end{array}$

25

17

$\begin{array}{llll}2 & 3 & 107\end{array}$

$\begin{array}{llllllllll}5 & 1 & 6 & 4 & 11 & 10 & 7 & 111\end{array}$

$2 \quad 26$

22

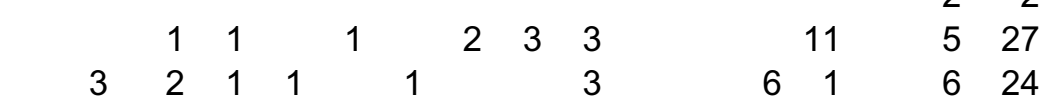

$\begin{array}{rrrrrrrrrr}3 & 2 & 1 & 1 & 1 & 3 & 6 & 1 & 6 & 24 \\ & & & & & & 1 & & 1\end{array}$

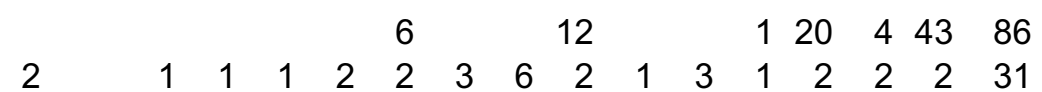

$\begin{array}{rllllllllllllll}2 & 2 & 3 & & & & & & & & & & & & \end{array}$

$\begin{array}{llllll}1 & 1 & 1 & 1 & 2 & 6\end{array}$

$\begin{array}{llll}1 & 1 & 2\end{array}$

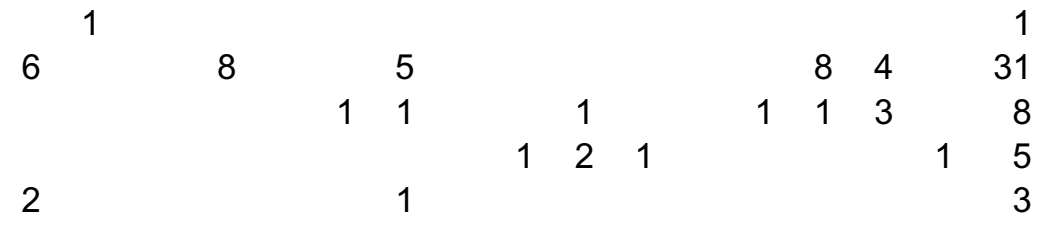

$\begin{array}{llllllllllll}5 & 2 & 1 & 4 & 1 & 2 & 1 & 3 & 2 & 3 & 1 & 25\end{array}$

$\begin{array}{llllllll}1 & & & & & & & \end{array}$

$\begin{array}{rrrrrrrrrrrrrrrrr}5 & 6 & 7 & 2 & 8 & 5 & 3 & 9 & 2 & 10 & 2 & 7 & 2 & 1 & 4 & 15 & 88\end{array}$

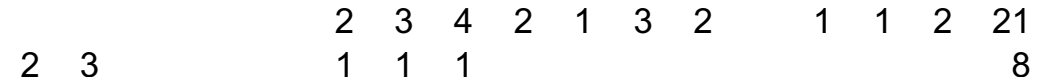

$\begin{array}{lllll}2 & 2 & 8 & 12\end{array}$

2 2

1 1

$\begin{array}{llllll}6 & 2 & 11 & 5 & 5 & 29\end{array}$

2

$\begin{array}{llll}1 & 1 & 1\end{array}$

$\begin{array}{rrrrrrr}1 & 3 & 1 & 2 & 5 & 1 & 13\end{array}$

$2 \quad 10 \quad 12$ 
Tabela 3 - Espécies de aranhas orbitelas associadas aos dois tipos de mata da Reserva do Morro Grande. A ordem das espécies reflete o grau de associação de maneira decrescente. Dados referentes às áreas amostradas na reserva, em dezembro/2002 e março/2003. Apenas as espécies com ao menos 10 indivíduos foram incluídas.

Table 3 - Orb-weaver spider species associated to the two types of forest found within the Reserva Florestal do Morro Grande. The order in which the species are placed in the table represents the degree of association in a decreasing manner. Data concerning areas sampled at the Reserva Florestal do Morro Grande in December/2002 and March/2003. Only species represented by at least 10 individuals were included.

\begin{tabular}{|c|c|c|c|}
\hline \multicolumn{2}{|c|}{ Floresta madura } & \multicolumn{2}{|c|}{ Floresta secundária } \\
\hline Família & Espécie & Família & Espécie \\
\hline Tetragnathidae & Chrysometa cambara & Araneidae & Alpaida scriba \\
\hline Araneidae & Micrathena nigrichelis & Araneidae & Wagneriana janeiro \\
\hline Araneidae & Mangora sp.5 & Tetragnathidae & Azilia sp.1 \\
\hline Araneidae & Micrathena triangularis & Araneidae & Alpaida aff. canoa \\
\hline Uloboridae & Miagrammopes sp.1 & Tetragnathidae & Chrysometa sumare \\
\hline Araneidae & Alpaida sp.1 & Araneidae & Cyclosa fililineata \\
\hline Tetragnathidae & Chrysometa Iudibunda & Araneidae & Verrucosa sp.1 \\
\hline Araneidae & Testudinaria sp.1 & Araneidae & Araneus orgaos \\
\hline Araneidae & Wagneriana iguape & Araneidae & Micrathena crassispina \\
\hline Tetragnathidae & Nephila clavipes & Araneidae & Wagneriana neglecta \\
\hline Araneidae & Araneus iguacu & Tetragnathidae & Chrysometa sp.1 \\
\hline Tetragnathidae & Azilia histrio & Araneidae & Acacesia sp.1 \\
\hline Araneidae & Micrathena guanabara & Araneidae & Araneus vincibilis \\
\hline Tetragnathidae & Chrysometa itaimba & Araneidae & Cyclosa morretes \\
\hline Tetragnathidae & Azilia sp.3 & Tetragnathidae & Homalometa sp.2 \\
\hline Araneidae & Alpaida pedro & Theridiosomatidae & Chthonos sp.1 \\
\hline Araneidae & Araneus omnicolor & Araneidae & Mangora sp.2 \\
\hline \multirow[t]{2}{*}{ Tetragnathidae } & Chrysometa boraceia & Theridiosomatidae & Ogulnius sp.1 \\
\hline & & Araneidae & Araneus sp.1 \\
\hline
\end{tabular}


Tabela 4. Metodologia empregada, número de indivíduos adultos e espécies de aranhas orbitelas e intensidade de coleta de levantamentos de araneofauna na Mata Atlântica. Métodos: CMN-coleta manual noturna; GCE-guarda-chuva entomológico; WIN-funil extrator de Winckler(fauna de folhiço); PIT-armadilhas de queda(fauna do solo). Obs: unidade amostral de CMN é 1 hora, para os demais métodos varia.

Table 4 - Collecting methods employed, number of adult individuals and richness of orb-weaver spiders and sampling intensity in Atlantic rainforest spider inventories. Methods: CMN - nocturnal manual collecting (=Looking up and down); GCE - beating-tray ; WIN - winkler extractor (litter fauna); PIT - pitfall-traps (ground fauna). Obs: Sampling units represent 1 hour of active collecting for CMN, while there is a great variation for the other methods.

\begin{tabular}{|c|c|c|c|c|c|c|}
\hline Levantamento & $\begin{array}{l}\text { Período de coleta } \\
\text { e número de } \\
\text { áreas } \\
\text { amostradas }\end{array}$ & Esforço amostral & $\begin{array}{l}\text { Método de } \\
\text { coleta }\end{array}$ & Abundância & spp. & $\begin{array}{c}\text { Intensidade. } \\
\text { De coleta }\end{array}$ \\
\hline $\begin{array}{c}\text { Brescovit et al. 2004b } \\
\text { Juréia-SP }\end{array}$ & $\begin{array}{c}4 \text { semanas } \\
\text { não fornece datas } \\
3 \text { áreas }\end{array}$ & não informa & $\begin{array}{l}\text { CMN } \\
\text { GCE } \\
\text { WIN } \\
\text { PIT }\end{array}$ & $\mathrm{X}$ & 71 & $\mathrm{X}$ \\
\hline $\begin{array}{l}\text { Santos } 1999 \\
\text { Linhares-ES }\end{array}$ & $\begin{array}{c}6 \text { dias - janeiro } \\
5 \text { dias - julho } \\
3 \text { áreas }\end{array}$ & $\begin{array}{l}76-\mathrm{CMN} \\
176-\mathrm{GCE}\end{array}$ & $\begin{array}{l}\mathrm{CMN} \\
\mathrm{GCE}\end{array}$ & 550 & 63 & $8,7: 1$ \\
\hline $\begin{array}{c}\text { Pinto-da-Rocha } \\
\text { Dados não publicados } \\
\text { Cantareira-SP }\end{array}$ & $\begin{array}{l}\text { Coletas a cada } 2 \\
\text { meses, ao longo } \\
\text { de um ano } \\
3 \text { áreas }\end{array}$ & $\begin{array}{c}239-\mathrm{CMN} \\
382-\mathrm{GCE} \\
205-\mathrm{WIN} \\
146-\mathrm{PIT}\end{array}$ & $\begin{array}{l}\text { CMN } \\
\text { GCE } \\
\text { WIN } \\
\text { PIT }\end{array}$ & 1051 & 72 & $14,6: 1$ \\
\hline $\begin{array}{l}\text { Presente trabalho } \\
\text { Cotia e Ibiuna-SP }\end{array}$ & $\begin{array}{c}16 \text { dias - } \\
\text { dezembro } \\
16 \text { dias - março } \\
16 \text { áreas }\end{array}$ & $384-\mathrm{CMN}$ & $\mathrm{CMN}$ & 3148 & 121 & $26: 1$ \\
\hline
\end{tabular}

http://www.biotaneotropica.org.br 
Tabela 5. Distribuição percentual da riqueza e abundância entre as famílias da guilda das orbitelas, em Morro Grande e região, em outros levantamentos, e em relação à riqueza do grupo no Brasil e no mundo.

* Amplitude dos valores encontrados em: Silva (1996), Silva \& Coddington (1996), Santos (1999), Höfer \& Brescovit (2001), Brescovit et al. (2004), Pinto-da-Rocha dados não publicados; ** Dados de 2002

*** Dados referentes à riqueza total do grupo (Platnick 2004); **** Amplitude dos valores encontrados em: Silva (1996), Silva \& Coddington (1996), Santos (1999), Pinto-da-Rocha dados não publicados; ***** Apenas o inventário de Silva (1996) dispõe de dados de abundância para essa família.

Table 5 - Percentage distribution of richness and abundance among orb-weaver families, at Reserva Florestal do Morro Grande and surrounding areas, in other inventories, and related to the richness of the group in Brazil and in the world. * Range of the values found at: Silva (1996), Silva \& Coddington (1996), Santos (1999), Höfer \& Brescovit (2001), Brescovit et al. (2004), Pinto-da-Rocha, unpublished data; ** Data from 2002

*** Data related to the total richness (Platnick 2004); **** Range of the values found at: Silva (1996), Silva \& Coddington (1996), Santos (1999), Pinto-da-Rocha, unpublished data; ***** Only Silva (1996) had data for that family.

\begin{tabular}{lcccccc}
\hline \multirow{2}{*}{ Família } & \multicolumn{3}{c}{ Riqueza } & \multicolumn{2}{c}{ Abundância } \\
\cline { 2 - 6 } & $\begin{array}{c}\text { Morro Grande } \\
\text { e região }\end{array}$ & Inventários* & $\begin{array}{c}\text { Riqueza no } \\
\text { Brasil** }\end{array}$ & $\begin{array}{c}\text { Riqueza } \\
\text { total*** }\end{array}$ & $\begin{array}{c}\text { Morro Grande } \\
\text { e região }\end{array}$ & $\begin{array}{l}\text { Inventários**** } \\
\text { Araneidae }\end{array}$ \\
Tetragnathidae & 21,8 & $61,7-73,3$ & 80,9 & 63,7 & 70,77 & $45,1-90,7$ \\
Theridiosomatidae & 7,5 & $10,1-25$ & 10 & 23 & 21,4 & $7,5-36,7$ \\
Uloboridae & 4,9 & $1,4-11,1$ & 3,9 & 5,5 & 5,3 & $1,2-12,5$ \\
Anapidae & 1,7 & $0,4-2,8$ & 0,9 & 3,2 & 0,4 & $0,5-14,9$ \\
Mysmenidae & 0,8 & $1,6-3,8$ & 0,4 & 2 & 0,2 & $0,1-2$ \\
Symphytognathidae & 0,8 & $0,6-1,6$ & 0,4 & 0,9 & 0,03 & $2,9-3,6$ \\
\hline
\end{tabular}

